\title{
A Dynamic Model of pH-induced Protein G'e Higher Order Structure Changes derived from Mass Spectrometric Analyses
}

\author{
Yelena Yefremova ${ }^{1)}$, Mahmoud Al-Majdoub ${ }^{1)}$, Kwabena F.M. Opuni ${ }^{11}$, Cornelia Koy ${ }^{11}$, \\ Yuetian $\mathrm{Yan}^{2)}$, Michael Gross ${ }^{2)}$, and Michael O. Glocker ${ }^{11}$
}

1) Proteome Center Rostock, University Medicine Rostock, Rostock, Germany

2) Department of Chemistry, Washington University in St. Louis, St. Louis, Missouri 63130 USA

E-mail: michael.glocker@med.uni-rostock.de

\section{Supporting Information}

$\begin{array}{ll}\text { Materials and Methods } & \text { S2 } \\ \text { Supplemental Tables } & \text { S5 } \\ \text { Supplemental Figures } & \text { S12 }\end{array}$




\section{Materials and methods}

Literature references in the supporting information have the same numbers as in the original text.

\section{NanoESI MS acquisition conditions}

Nano-electrospray ionization (nanoESI) mass spectrometry was performed with protein G'e by using a Waters ESI Q-ToF II mass spectrometer (Waters MS-Technologies, Manchester, UK). NanoESI capillaries were prepared in-house from borosilicate glass tubes of $1 \mathrm{~mm}$ outer and $0.5 \mathrm{~mm}$ inner diameters (Sutter Instrument, Novato, CA, USA) using a P-1000 Flaming/Brown ${ }^{\top M}$ Micropipette Puller System (Sutter Instrument, Novato, CA, USA). Coating with gold was achieved using a sputter coater BalTec SCD 004 (Bal-Tec, Balzers, Liechtenstein). Protein G'e $(0.5 \mu \mathrm{g} / \mu \mathrm{L})$ was dissolved in a) $2 \%$ aqueous acetic acid:MeOH (95:5, v/v), pH 2.5, b) 50 mM aqueous ammonium acetate:MeOH (95:5, v/v), $\mathrm{pH} 7$. A volume of $5 \mu \mathrm{L}$ of each solution was loaded into custom-prepared capillaries by using a microloader pipette tip (Eppendorf, Hamburg, Germany). Mass spectra were acquired in the positive-ion mode setting the mass window to $\mathrm{m} / \mathrm{z} 100-4000$. The following experimental parameters were used for all measurements: capillary voltage, $1.5 \mathrm{kV}$; extractor cone, $3 \mathrm{~V}$; RF lens, 1.2 V; nitrogen counter flow gas, $50 \mathrm{l} / \mathrm{h}$; scan rate, $7 \mathrm{~s} / \mathrm{scan}$; digitization rate, $4 \mathrm{GHz}$; microchannel plate detector voltage, $1950 \mathrm{~V}$. The sample cone voltage was set to $40 \mathrm{~V}$ or to $80 \mathrm{~V}$, and source temperature was $20^{\circ} \mathrm{C}$ or $30{ }^{\circ} \mathrm{C}$ for samples with acidic or with neutral pH values, respectively. Data acquisition and processing was performed with the MassLynx software version 4.0 (Waters MS-Technologies, Manchester, UK). External calibration was performed with $1 \%$ phosphoric acid dissolved in a trifluoroethanol/water solution (50:50, $\mathrm{v} / \mathrm{v})^{32,39}$

\section{Ion mobility - mass spectrometry and CCS calculations}

NanoESI-IM-MS of protein G'e dissolved in solvents at either neutral or acidic pH (see above) was performed on a Synapt G2-S mass spectrometer (Waters MS-Technologies, 
Manchester, UK) equipped with a nanoESI source and a traveling-wave ion mobility cell (TW-IMS). The instrumental parameters were optimized as follows: capillary voltage, $2 \mathrm{kV}$; sample cone, $40 \mathrm{~V}$; source temperature, $30{ }^{\circ} \mathrm{C}$; source offset, $40 \mathrm{~V}$; trap collision energy, $4 \mathrm{~V}$; transfer collision energy, $2 \mathrm{~V}$; trap gas flow, $2 \mathrm{~mL} / \mathrm{min}$; helium cell gas flow, $180 \mathrm{~mL} / \mathrm{min}$; IM gas flow, $60 \mathrm{~mL} / \mathrm{min}$; trap DC bias, $45 \mathrm{~V}$. EDC delay coefficient of the instrument was 1.41 . TW-IM was operated under acidic solvent conditions at wave velocities of 700,800 , and 900 $\mathrm{m} / \mathrm{s}$ and wave amplitude of $35 \mathrm{~V}$, whereas under neutral solvent conditions, a wave velocity of $600 \mathrm{~m} / \mathrm{s}$ and wave amplitudes of 30,35, and $40 \mathrm{~V}$ were applied. External mass calibration was performed with $1 \mathrm{mg} / \mathrm{mL}$ sodium iodide dissolved in an isopropanol/water solution $(50: 50, v / v)$. Calibration of the TW-IM drift times for protein G'e CCS determination was performed by using $15+$ to $24+$ ions from myoglobin and $13+$ to $19+$ ions from cytochrome $\mathrm{C}$. Calibrants were prepared at concentrations of $10 \mu \mathrm{M}$ in $\mathrm{MeOH}: \mathrm{H}_{2} \mathrm{O}_{2}$ :acetic acid (49:49:2, $\mathrm{v} / \mathrm{v} / \mathrm{v}), \mathrm{pH} 2.5$. IM-MS data were recorded using the same instrumental conditions which were first optimized for protein G'e samples. Linear calibration plots were created using corrected CCS from literature values of the absolute CCS of denatured myoglobin and cytochrome C. Calculation of protein G'e CCS was performed using published protocols. ${ }^{40-42}$

To estimate the oxidation rate of protein G'e samples on a global level the remaining unoxidized fraction was calculated using the following equation:

$$
\text { Remaining unoxidized fraction }(\%)=\left(\sum I / \sum I_{\text {ox }}+\sum I\right)^{*} 100
$$

Where $I$ is the intensity of the ion peak of the unmodified protein, $I_{o x}$ is the intensities of all ion peaks that correspond to (multiply) oxidized protein.

\section{CD spectroscopy acquisition conditions}

The following settings were applied: continuous scanning mode; $50 \mathrm{~nm} / \mathrm{min}$ scanning speed, $8 \mathrm{~s}$ response time, and $1 \mathrm{~nm}$ band width. Absorbance of the corresponding buffer solution was subtracted from each sample spectrum and CD spectra from six individual measurements were averaged. Secondary structure content estimation was done using the 
Spectra Manager Software version 1.5 (JASCO Corporation, Japan), and data visualization was performed with the Origin Software, version 6.1G (OriginLab Corp., Northampton, MA, USA). ${ }^{43}$

\section{LC-ESI MS of FPOP labeled samples}

From each FPOP and control sample, $4 \mu \mathrm{L}$ was mixed with $46 \mu \mathrm{L}$ of $0.1 \%$ formic acid (FA) to generate the "oxidized protein G'e" and "control protein G'e" samples. ${ }^{44}$ Then, $50 \mu \mathrm{L}$ of each sample were loaded on a $2 \times 15 \mathrm{~mm}$ C8 trap column (Agilent, Santa Clara, CA, USA) and desalted with a 3 min flow of $0.1 \%$ TFA in $\mathrm{H}_{2} \mathrm{O}$ at $200 \mu \mathrm{L} / \mathrm{min}$. The protein was then eluted with a two-step linear gradient from $4 \%$ to $40 \%$ of $0.1 \%$ TFA in $\mathrm{CH}_{3} \mathrm{CN}$ within 5.5 min and then to $80 \%$ of $0.1 \%$ TFA in $\mathrm{CH}_{3} \mathrm{CN}$ within $3 \mathrm{~min}$ at $200 \mu \mathrm{L} / \mathrm{min}$. Mass detection of the intact unmodified and modified proteins was performed on a Bruker MaXis Q-TOF mass spectrometer connected with an ESI source. Subsequent data analyses were performed using the Data Analysis Software Version 4.0 (Bruker Daltonics). ${ }^{45}$

\section{Enzymatic digestion of FPOP labeled protein G'e}

A volume of $12 \mu \mathrm{L}$ of each FPOP and control sample was lyophylized and resolubilized by adding $10 \mu \mathrm{L}$ of $8 \mathrm{M}$ urea. For digestion, a trypsin/Lys-C enzyme mix (Promega, Madison, WI, USA) was applied with an enzyme to substrate ratio of 1:20. Upon addition of the enzymes, the samples were diluted to a final volume of $75 \mu \mathrm{L}$ with $10 \mathrm{mM}$ PBS and incubated at $37^{\circ} \mathrm{C}$ while shaking at $500 \mathrm{rpm}$ overnight. Digestion was stopped by addition of FA to a final conc. of $1 \%$. Aliquots $(25 \mu \mathrm{L})$ of the trypsin/Lys-C digests were desalted with NT2 C18.96 ZipTips (Glygen, Columbia, MD, USA) and eluted with $10 \mu \mathrm{L}$ of $60 \%$ ACN, $0.1 \% \mathrm{FA}$. 


\section{Supplemental Tables}

Supplemental Table 1: Secondary structure content of protein G'e in $10 \mathrm{mM}$ aquoeus ammonium acetate buffer, $\mathrm{pH} 7^{\text {a) }}$

\begin{tabular}{cccc}
\hline no. of measurement & a-helix [\%] & $\boldsymbol{\beta}$-sheet [\%] & turn / random [\%] \\
\hline 1 & 30.5 & 47.4 & 22.1 \\
2 & 26.6 & 45.9 & 27.5 \\
3 & 24.6 & 48.3 & 27.1 \\
4 & 30.9 & 41.7 & 27.4 \\
5 & 25.9 & 49.3 & 24.7 \\
6 & 27.5 & 50.1 & 22.5 \\
meantSD & $27.7 \pm 2.5$ & $47.1 \pm 3.0$ & $22.2 \pm 2.5$ \\
\hline
\end{tabular}

a) cf. Supplemental Figure 3

Supplemental Table 2: Secondary structure content of protein G'e in 2\% aquoeus acetic acid, $\mathrm{pH} 2.5^{\text {a) }}$

\begin{tabular}{cccc}
\hline no. of measurement & $\boldsymbol{\alpha}$-helix [\%] & $\boldsymbol{\beta}$-sheet [\%] & turn / random [\%] \\
\hline 1 & 22.2 & 51.3 & 26.5 \\
2 & 21.0 & 52.6 & 26.4 \\
4 & 18.3 & 54.8 & 26.9 \\
5 & 22.9 & 50.3 & 26.8 \\
6 & 21.4 & 50.2 & 28.4 \\
mean \pm SD & 21.2 & 51.6 & 27.2 \\
\end{tabular}

a) cf. Supplemental Figure 3 
Supplemental Table 3: CCS values of multiply charged ions of trypsin-derived fragments "a", "b", and "c" of protein G'e ${ }^{a, b)}$

\begin{tabular}{cccc}
\hline Charge state & "a" $\left[\AA^{2}\right]$ & "b" $\left[\AA^{2}\right]$ & "c" $\left[\AA^{2}\right]$ \\
\hline & 2218 & & \\
$8+$ & 2464 & 2317 & n.d. \\
& 2990 & & \\
& 2477 & 2422 & n.d. \\
$9+$ & 2811 & 2959 & \\
& 3346 & 3207 & n.d. \\
$10+$ & 3288 & 3842 & n.d. \\
$11+$ & n.d. & n.d. & n.d. \\
$12+$ & 4488 & n.d. & n.d. \\
$13+$ & 4437 & n.d. & n.d. \\
$14+$ & 4463 & n.d. & n.d. \\
$15+$ & n.d. & 5369 & 5228 \\
$16+$ & n.d. & 5413 & 5304 \\
$17+$ & 5704 & 5458 & 5354 \\
$18+$ & 5770 & 5517 & 5422 \\
$19+$ & 5801 & 5593 & 5558 \\
$20+$ & 5893 & 5693 & 5681 \\
$21+$ & 5962 & 5775 & n.d. \\
$22+$ & 6058 & 5890 & n.d. \\
$23+$ & 6136 & n.d. & n.d. \\
$24+$ & 6249 & n.d. & \\
$25+$ & 6402 & &
\end{tabular}

a) cf. Supplemental Figure 4

b) Experimental molecular masses: $24,249.35 \pm 0.49 \mathrm{Da}$ (a), 22,731.56 \pm 0.87 (b), and 21,801.02 \pm 0.65 (c).

n.d.: not detected 
Supplemental Table 4: Ion signal assignments of chromatographic peaks with tryptic peptides from protein $\mathrm{G}^{\prime} \mathrm{e}$ incubated with $\mathrm{H}_{2} \mathrm{O}_{2}$ in $2 \%$ aquoeus acetic acid, $\mathrm{pH} 2.5$.

\begin{tabular}{|c|c|c|c|c|c|}
\hline fr. no. & $\mathbf{m} / \mathbf{z}$ & $\mathbf{z}$ & exp. mass & T no. ${ }^{\text {a) }}$ & amino acid sequence / oxidation \\
\hline 3 & $\begin{array}{l}621.020 \\
827.691\end{array}$ & $\begin{array}{l}4+ \\
3+\end{array}$ & $\begin{array}{l}2480.050 \\
2480.051\end{array}$ & $\begin{array}{l}\text { T2-T3 } \\
\text { T2-T3 }\end{array}$ & $\begin{array}{l}\text { GSHMASMTGGQQMGRDPNSSSVDK + } 1 \text { oxidation } \\
\text { GSHMASMTGGQQMGRDPNSSSVDK + } 1 \text { oxidation }\end{array}$ \\
\hline 4 & $\begin{array}{l}621.020 \\
827.691\end{array}$ & $\begin{array}{l}4+ \\
3+\end{array}$ & $\begin{array}{l}2480.051 \\
2480.052\end{array}$ & $\begin{array}{l}\text { T2-T3 } \\
\text { T2-T3 }\end{array}$ & $\begin{array}{l}\text { GSHMASMTGGQQMGRDPNSSSVDK + } 1 \text { oxidation } \\
\text { GSHMASMTGGQQMGRDPNSSSVDK + } 1 \text { oxidation }\end{array}$ \\
\hline 5 & $\begin{array}{l}621.019 \\
695.310 \\
827.690\end{array}$ & $\begin{array}{l}4+ \\
2+ \\
3+\end{array}$ & $\begin{array}{l}2480.047 \\
1388.605 \\
2480.048\end{array}$ & $\begin{array}{l}\text { T2-T3 } \\
- \\
\text { T2-T3 }\end{array}$ & $\begin{array}{l}\text { GSHMASMTGGQQMGRDPNSSSVDK + } 1 \text { oxidation } \\
- \\
\text { GSHMASMTGGQQMGRDPNSSSVDK + } 1 \text { oxidation }\end{array}$ \\
\hline 6 & $\begin{array}{l}617.021 \\
822.359\end{array}$ & $\begin{array}{l}4+ \\
3+\end{array}$ & $\begin{array}{l}2464.054 \\
2464.055\end{array}$ & $\begin{array}{l}\text { T2-T3 } \\
\text { T2-T3 }\end{array}$ & $\begin{array}{l}\text { GSHMASMTGGQQMGRDPNSSSVDK } \\
\text { GSHMASMTGGQQMGRDPNSSSVDK }\end{array}$ \\
\hline 7 & $\begin{array}{l}498.570 \\
747.353\end{array}$ & $\begin{array}{l}3+ \\
2+\end{array}$ & $\begin{array}{l}1492.689 \\
1492.691\end{array}$ & $\begin{array}{l}\text { T7 / T13 } \\
\text { T7 / T13 }\end{array}$ & $\begin{array}{l}\text { GETTTEAVDAATAEK } \\
\text { GETTTEAVDAATAEK }\end{array}$ \\
\hline 8 & $\begin{array}{l}612.646 \\
918.466\end{array}$ & $\begin{array}{l}3+ \\
2+\end{array}$ & $\begin{array}{l}1834.918 \\
1834.918\end{array}$ & $\begin{array}{l}\text { T6-T7 / } \\
\text { T12-T13 } \\
\text { T6-T7 / } \\
\text { T12-T13 }\end{array}$ & $\begin{array}{l}\text { TLKGETTTEAVDAATAEK } \\
\text { TLKGETTTEAVDAATAEK }\end{array}$ \\
\hline 9 & $\begin{array}{l}490.276 \\
979.547\end{array}$ & $\begin{array}{l}2+ \\
1+\end{array}$ & $\begin{array}{l}978.538 \\
978.540\end{array}$ & $\begin{array}{l}\mathrm{T} 4 \\
\mathrm{~T} 4\end{array}$ & $\begin{array}{l}\text { LAAALETYK } \\
\text { LAAALETYK }\end{array}$ \\
\hline 12 & $\begin{array}{c}721.304 \\
726.980 \\
728.630 \\
733.954 \\
1081.453\end{array}$ & $\begin{array}{l}3+ \\
3+ \\
3+ \\
3+ \\
2+\end{array}$ & $\begin{array}{l}2160.890 \\
2177.917 \\
2182.869 \\
2198.841 \\
2160.892\end{array}$ & $\begin{array}{l}\text { T9 / T15 } \\
\text { T9 / T15 } \\
\text { T9 / T15 } \\
\text { T9 / T15 } \\
\text { T9 / T15 }\end{array}$ & $\begin{array}{l}\text { QYANDNGVDGEWTYDDATK } \\
\text { QYANDNGVDGEWTYDDATK + 1 oxidation + deamidation } \\
\text { QYANDNGVDGEWTYDDATK + Sodium } \\
\text { QYANDNGVDGEWTYDDATK + Potassium } \\
\text { QYANDNGVDGEWTYDDATK }\end{array}$ \\
\hline 13 & $\begin{array}{r}691.379 \\
711.313 \\
716.988 \\
718.639 \\
723.961 \\
921.503 \\
1066.466\end{array}$ & $\begin{array}{l}4+ \\
3+ \\
3+ \\
3+ \\
3+ \\
3+ \\
2+\end{array}$ & $\begin{array}{l}2761.486 \\
2130.917 \\
2147.943 \\
2152.896 \\
2168.860 \\
2761.487 \\
2130.918\end{array}$ & $\begin{array}{l}- \\
\text { T22 } \\
\text { T22 } \\
\text { T22 } \\
\text { T22 } \\
- \\
\text { T22 }\end{array}$ & $\begin{array}{l}- \\
\text { QYANDNGVDGVWTYDDATK } \\
\text { QYANDNGVDGVWTYDDATK + } 1 \text { oxidation + deamidation } \\
\text { QYANDNGVDGVWTYDDATK + Sodium } \\
\text { QYANDNGVDGVWTYDDATK + Potassium } \\
\text { - } \\
\text { QYANDNGVDGVWTYDDATK }\end{array}$ \\
\hline 15 & $\begin{array}{l}880.795 \\
980.175 \\
1320.688\end{array}$ & $\begin{array}{l}3+ \\
3+ \\
2+\end{array}$ & $\begin{array}{l}2639.363 \\
2937.503 \\
2639.361\end{array}$ & $\begin{array}{l}\mathrm{T} 10 / \mathrm{T} 16 \\
- \\
\mathrm{T} 10 / \mathrm{T} 16\end{array}$ & $\begin{array}{l}\text { TFTVTEKPEVIDASELTPAVTTYK } \\
- \\
\text { TFTVTEKPEVIDASELTPAVTTYK }\end{array}$ \\
\hline 16 & $\begin{array}{r}501.607 \\
751.907 \\
1035.402 \\
1183.172 \\
1380.199\end{array}$ & $\begin{array}{l}3+ \\
2+ \\
8+ \\
7+ \\
6+\end{array}$ & $\begin{array}{l}1501.798 \\
1501.800 \\
8275.155 \\
8275.156 \\
8275.153\end{array}$ & $\begin{array}{l}- \\
- \\
\text { T16-T23 } \\
\text { T16-T23 } \\
\text { T16-T23 }\end{array}$ & $\begin{array}{l}- \\
- \\
\text { TFTVTEKPEVIDASELTPAVTTYKLVINGKTLKGETTTKA } \\
\text { VDAETAEKAFKQYANDNGVDGVWTYDDATKTFTVTE }\end{array}$ \\
\hline \multirow[t]{3}{*}{17} & $\begin{array}{l}1072.546 \\
1225.624 \\
1429.727\end{array}$ & $\begin{array}{l}8+ \\
7+ \\
6+\end{array}$ & $\begin{array}{l}8572.310 \\
8572.314 \\
8572.318\end{array}$ & $\begin{array}{l}\mathrm{T} 4-\mathrm{T} 10 \\
\mathrm{~T} 4-\mathrm{T} 10 \\
\mathrm{~T} 4-\mathrm{T} 10\end{array}$ & $\begin{array}{l}\text { LAAALETYKLILNGKTLKGETTTEAVDAATAEKVFKQYA } \\
\text { NDNGVDGEWTYDDATKTFTVTEKPEVIDASELTPAVTTYK }\end{array}$ \\
\hline & $\begin{array}{l}1278.396 \\
1460.879\end{array}$ & $\begin{array}{l}8+ \\
7+\end{array}$ & $\begin{array}{l}10219.110 \\
10219.101\end{array}$ & $\begin{array}{l}\text { T10-T16 } \\
\text { T10-T16 }\end{array}$ & $\begin{array}{l}\text { TFTVTEKPEVIDASELTPAVTTYKLVINGKTLKGETTTEA } \\
\text { VDAATAEKVFKQYANDNGVDGEWTYDDATKTFTVTEKPE } \\
\text { VIDASELTPAVTTYK } \\
\text { TFTVTEKPEVIDASELTPAVTTYKLVINGKTLKGETTTEA }\end{array}$ \\
\hline & $\begin{array}{l}1442.270 \\
1586.396\end{array}$ & $\begin{array}{l}11+ \\
10+\end{array}$ & $\begin{array}{l}15853.894 \\
15853.887\end{array}$ & $\begin{array}{l}\text { T10-T23 } \\
\text { T10-T23 }\end{array}$ & $\begin{array}{l}\text { VDAATAEKVFKQYANDNGVDGEWTYDDATKTFTVTEKPE } \\
\text { VIDASELTPAVTTYKLVINGKTLKGETTTKAVDAETAEKA } \\
\text { FKQYANDNGVDGVWTYDDATKTFTVTE }\end{array}$ \\
\hline
\end{tabular}

a) tryptic peptide number, see figure 2

"-“": not assigned 
Supplemental Table 5: Ion signal assignments of chromatographic peaks with tryptic peptides from protein G'e after FPOP in $50 \mathrm{mM}$ aquoeus ammonium acetate, $\mathrm{pH} 7{ }^{\text {a) }}$.

\begin{tabular}{|c|c|c|c|c|c|}
\hline fr. no. & $\mathbf{m} / \mathbf{z}$ & $\mathbf{z}$ & exp. mass & T no. ${ }^{b)}$ & amino acid sequence / oxidation \\
\hline 1 & $\begin{array}{l}625.018 \\
833.023\end{array}$ & $\begin{array}{l}4+ \\
3+\end{array}$ & $\begin{array}{l}2496.044 \\
2496.045\end{array}$ & $\begin{array}{l}\text { T2-T3 } \\
\text { T2-T3 }\end{array}$ & $\begin{array}{l}\text { GSHMASMTGGQQMGRDPNSSSVDK + } 2 \text { oxidations } \\
\text { GSHMASMTGGQQMGRDPNSSSVDK + } 2 \text { oxidations }\end{array}$ \\
\hline 2 & $\begin{array}{l}625.018 \\
833.024\end{array}$ & $\begin{array}{l}4+ \\
3+\end{array}$ & $\begin{array}{l}2496.044 \\
2496.045\end{array}$ & $\begin{array}{l}\text { T2-T3 } \\
\text { T2-T3 }\end{array}$ & $\begin{array}{l}\text { GSHMASMTGGQQMGRDPNSSSVDK + } 2 \text { oxidations } \\
\text { GSHMASMTGGQQMGRDPNSSSVDK + } 2 \text { oxidations }\end{array}$ \\
\hline 3 & $\begin{array}{l}621.018 \\
625.016 \\
827.691\end{array}$ & $\begin{array}{l}4+ \\
4+ \\
3+\end{array}$ & $\begin{array}{l}2480.044 \\
2496.034 \\
2480.044\end{array}$ & $\begin{array}{l}\text { T2-T3 } \\
\text { T2-T3 } \\
\text { T2-T3 }\end{array}$ & $\begin{array}{l}\text { GSHMASMTGGQQMGRDPNSSSVDK + } 1 \text { oxidation } \\
\text { GSHMASMTGGQQMGRDPNSSSVDK + } 2 \text { oxidations } \\
\text { GSHMASMTGGQQMGRDPNSSSVDK + } 1 \text { oxidation }\end{array}$ \\
\hline 4 & $\begin{array}{l}621.02 \\
625.018 \\
827.691\end{array}$ & $\begin{array}{l}4+ \\
4+ \\
3+\end{array}$ & $\begin{array}{l}2480.051 \\
2496.041 \\
2480.052\end{array}$ & $\begin{array}{l}\text { T2-T3 } \\
\text { T2-T3 } \\
\text { T2-T3 }\end{array}$ & $\begin{array}{l}\text { GSHMASMTGGQQMGRDPNSSSVDK + } \mathbf{1} \text { oxidation } \\
\text { GSHMASMTGGQQMGRDPNSSSVDK + } \mathbf{2} \text { oxidations } \\
\text { GSHMASMTGGQQMGRDPNSSSVDK + } \mathbf{1} \text { oxidation }\end{array}$ \\
\hline 5 & $\begin{array}{l}621.019 \\
827.69\end{array}$ & $\begin{array}{l}4+ \\
3+\end{array}$ & $\begin{array}{l}2480.048 \\
2480.048\end{array}$ & $\begin{array}{l}\text { T2-T3 } \\
\text { T2-T3 }\end{array}$ & $\begin{array}{l}\text { GSHMASMTGGQQMGRDPNSSSVDK + } 1 \text { oxidation } \\
\text { GSHMASMTGGQQMGRDPNSSSVDK + } 1 \text { oxidation }\end{array}$ \\
\hline 6 & $\begin{array}{l}617.021 \\
822.359\end{array}$ & $\begin{array}{l}4+ \\
3+\end{array}$ & $\begin{array}{l}2464.055 \\
2464.055\end{array}$ & $\begin{array}{l}\text { T2-T3 } \\
\text { T2-T3 }\end{array}$ & $\begin{array}{l}\text { GSHMASMTGGQQMGRDPNSSSVDK } \\
\text { GSHMASMTGGQQMGRDPNSSSVDK }\end{array}$ \\
\hline 7 & $\begin{array}{l}498.570 \\
747.353 \\
996.135\end{array}$ & $\begin{array}{l}3+ \\
2+ \\
3+\end{array}$ & $\begin{array}{l}1492.689 \\
1492.691 \\
2985.383\end{array}$ & $\begin{array}{l}\text { T7 / T13 } \\
\text { T7 / T13 } \\
\quad-\end{array}$ & $\begin{array}{l}\text { GETTTEAVDAATAEK } \\
\text { GETTTEAVDAATAEK } \\
-\end{array}$ \\
\hline 8 & $\begin{array}{l}612.646 \\
918.466\end{array}$ & $\begin{array}{l}3+ \\
2+\end{array}$ & $\begin{array}{l}1834.917 \\
1834.918\end{array}$ & $\begin{array}{l}\text { T6-T7 / } \\
\text { T12-T13 } \\
\text { T6-T7 / } \\
\text { T12-T13 }\end{array}$ & $\begin{array}{l}\text { TLKGETTTEAVDAATAEK } \\
\text { TLKGETTTEAVDAATAEK }\end{array}$ \\
\hline 9 & $\begin{array}{l}490.276 \\
979.546\end{array}$ & $\begin{array}{l}2+ \\
1+\end{array}$ & $\begin{array}{l}978.537 \\
978.539\end{array}$ & $\begin{array}{l}\text { T4 } \\
\text { T4 }\end{array}$ & $\begin{array}{l}\text { LAAALETYK } \\
\text { LAAALETYK }\end{array}$ \\
\hline 10 & $\begin{array}{c}698.355 \\
726.636 \\
768.855 \\
1089.451\end{array}$ & $\begin{array}{l}2+ \\
3+ \\
2+ \\
2+\end{array}$ & $\begin{array}{l}1394.695 \\
2176.886 \\
1535.696 \\
2176.879\end{array}$ & $\begin{array}{l}- \\
\text { T9 / T15 } \\
\text { T2 } \\
\text { T9 / T15 }\end{array}$ & $\begin{array}{l}- \\
\text { QYANDNGVDGEWTYDDATK + } 1 \text { oxidation } \\
\text { GSHMASMTGGQQMGR } \\
\text { QYANDNGVDGEWTYDDATK + } \mathbf{1} \text { oxidation }\end{array}$ \\
\hline 11 & $\begin{array}{c}698.355 \\
726.636 \\
731.967 \\
737.643 \\
739.294 \\
754.342 \\
768.855 \\
1089.451 \\
1097.447\end{array}$ & $\begin{array}{l}2+ \\
3+ \\
3+ \\
3+ \\
3+ \\
2+ \\
2+ \\
2+ \\
2+\end{array}$ & $\begin{array}{l}1394.695 \\
2176.886 \\
2192.879 \\
2209.906 \\
2214.860 \\
1506.669 \\
1535.696 \\
2176.879 \\
2192.873\end{array}$ & $\begin{array}{l}\text { T9 / T15 } \\
\text { T9 / T15 } \\
\text { T9 / T15 } \\
\text { T9 / T15 } \\
\quad- \\
\text { T2 } \\
\text { T9 / T15 } \\
\text { T9 / T15 }\end{array}$ & $\begin{array}{l}- \\
\text { QYANDNGVDGEWTYDDATK + } \mathbf{1} \text { oxidation } \\
\text { QYANDNGVDGEWTYDDATK }+\mathbf{2} \text { oxidations } \\
\text { QYANDNGVDGEWTYDDATK }+\mathbf{3} \text { oxidations + deamidation } \\
\text { QYANDNGVDGEWTYDDATK + } \mathbf{2} \text { oxidations + Sodium } \\
- \\
\text { GSHMASMTGGQQMGR } \\
\text { QYANDNGVDGEWTYDDATK + } \mathbf{1} \text { oxidation } \\
\text { QYANDNGVDGEWTYDDATK + } \mathbf{2} \text { oxidations }\end{array}$ \\
\hline 12 & $\begin{array}{c}721.303 \\
726.978 \\
728.629 \\
733.951 \\
1081.452\end{array}$ & $\begin{array}{l}3+ \\
3+ \\
3+ \\
3+ \\
2+\end{array}$ & $\begin{array}{l}2160.888 \\
2177.913 \\
2182.866 \\
2198.831 \\
2160.889\end{array}$ & $\begin{array}{l}\text { T9 / T15 } \\
\text { T9 / T15 } \\
\text { T9 / T15 } \\
\text { T9 / T15 } \\
\text { T9 / T15 }\end{array}$ & $\begin{array}{l}\text { QYANDNGVDGEWTYDDATK } \\
\text { QYANDNGVDGEWTYDDATK + 1 oxidation + deamidation } \\
\text { QYANDNGVDGEWTYDDATK + Sodium } \\
\text { QYANDNGVDGEWTYDDATK + Potassium } \\
\text { QYANDNGVDGEWTYDDATK }\end{array}$ \\
\hline 13 & $\begin{array}{r}711.314 \\
716.988 \\
718.639 \\
723.961 \\
885.456 \\
886.125 \\
1066.466\end{array}$ & $\begin{array}{l}3+ \\
3+ \\
3+ \\
3+ \\
3+ \\
3+ \\
2+\end{array}$ & $\begin{array}{l}2130.917 \\
2147.943 \\
2152.896 \\
2168.861 \\
2653.345 \\
2655.356 \\
2130.918\end{array}$ & $\begin{array}{l}\text { T22 } \\
\text { T22 } \\
\text { T22 } \\
\text { T22 } \\
\mathrm{T} 10 / \mathrm{T} 16 \\
\mathrm{~T} 10 / \mathrm{T} 16 \\
\mathrm{~T} 22\end{array}$ & $\begin{array}{l}\text { QYANDNGVDGVWTYDDATK } \\
\text { QYANDNGVDGVWTYDDATK + 1 oxidation + deamidation } \\
\text { QYANDNGVDGVWTYDDATK + Sodium } \\
\text { QYANDNGVDGVWTYDDATK + Potassium } \\
\text { TFTVTEKPEVIDASELTPAVTTYK + co form. by oxidation } \\
\text { TFTVTEKPEVIDASELTPAVTTYK + 1 oxidation } \\
\text { QYANDNGVDGVWTYDDATK }\end{array}$ \\
\hline 14 & $\begin{array}{c}728.277 \\
886.126 \\
1072.941 \\
1081.453 \\
1083.930\end{array}$ & $\begin{array}{l}3+ \\
3+ \\
2+ \\
2+ \\
2+\end{array}$ & $\begin{array}{l}2181.809 \\
2655.356 \\
2143.867 \\
2160.892 \\
2165.844\end{array}$ & $\begin{array}{l}- \\
\text { T10 / T16 } \\
\text { T9 / T15 } \\
\text { T9 / T15 } \\
\text { T9 / T15 }\end{array}$ & $\begin{array}{l}- \\
\text { TFTVTEKPEVIDASELTPAVTTYK + } 1 \text { oxidation } \\
\text { pQYANDNGVDGEWTYDDATK } \\
\text { QYANDNGVDGEWTYDDATK } \\
\text { pQYANDNGVDGEWTYDDATK + Sodium }\end{array}$ \\
\hline
\end{tabular}




\begin{tabular}{cccccl}
\hline fr. no. & $\mathbf{m} / \mathbf{z}$ & $\mathbf{z}$ & exp. mass & T no. $^{\mathbf{b})}$ & amino acid sequence / oxidation \\
\hline \multirow{2}{*}{15} & 866.122 & $3+$ & 2595.343 & - & - \\
& 880.795 & $3+$ & 2639.362 & T10/T16 & TFTVTEKPEVIDASELTPAVTTYK \\
& 1320.688 & $2+$ & 2639.362 & T10/T16 & TFTVTEKPEVIDASELTPAVTTYK \\
16 & 895.131 & $3+$ & 2682.370 & - & - \\
& 1035.403 & $8+$ & 8275.164 & T16-T23 & \\
& 1183.174 & $7+$ & 8275.165 & T16-T23 & TFTVTEKPEVIDASELTPAVTTYKLVINGKTLKGETTTKAVD \\
& 1380.201 & $6+$ & 8275.162 & T16-T23 & AETAEKAFKQYANDNGVDGVWTYDDATKTFTVTE \\
& 1072.549 & $8+$ & 8572.337 & T4-T10 & \\
& 1225.628 & $7+$ & 8572.342 & T4-T10 & LAAALETYKLILNGKTLKGETTTEAVDAATAEKVFKQYAND \\
& 1429.732 & $6+$ & 8572.346 & T4-T10 & NGVDGEWTYDDATKTFTVTEKPEVIDASELTPAVTTYK \\
& 1136.468 & $9+$ & 10219.147 & T10-T16 & TFTVTEKPEVIDASELTPAVTTYKLVINGKTLKGETTTEAVD \\
& 1278.275 & $8+$ & 10218.140 & T10-T16 & AATAEKVFKQYANDNGVDGEWTYDDATKTFTVTEKPEVI \\
& 1460.740 & $7+$ & 10218.130 & T10-T16 & DASELTPAVTTYK \\
\hline
\end{tabular}

a) cf. figure $3 \mathrm{~A}$

b) tryptic peptide number, see figure 2

"-": not assigned 
Supplemental Table 6: Ion signal assignments of chromatographic peaks with tryptic peptides from protein G'e after FPOP in $2 \%$ aquoeus acetic acid, $\mathrm{pH} 2.5^{\mathrm{a}}$.

\begin{tabular}{|c|c|c|c|c|c|}
\hline fr. no. & $\mathbf{m} / \mathbf{z}$ & $\mathbf{z}$ & exp. mass & T no. ${ }^{b)}$ & amino acid sequence / oxidation \\
\hline 1 & $\begin{array}{l}625.019 \\
833.023\end{array}$ & $\begin{array}{l}4+ \\
3+\end{array}$ & $\begin{array}{l}2496.045 \\
2496.046\end{array}$ & $\begin{array}{l}\text { T2-T3 } \\
\text { T2-T3 }\end{array}$ & $\begin{array}{l}\text { GSHMASMTGGQQMGRDPNSSSVDK + } 2 \text { oxidations } \\
\text { GSHMASMTGGQQMGRDPNSSSVDK + } 2 \text { oxidations }\end{array}$ \\
\hline 2 & $\begin{array}{l}625.019 \\
833.023\end{array}$ & $\begin{array}{l}4+ \\
3+\end{array}$ & $\begin{array}{l}2496.046 \\
2496.047\end{array}$ & $\begin{array}{l}\text { T2-T3 } \\
\text { T2-T3 }\end{array}$ & $\begin{array}{l}\text { GSHMASMTGGQQMGRDPNSSSVDK + } 2 \text { oxidations } \\
\text { GSHMASMTGGQQMGRDPNSSSVDK + } 2 \text { oxidations }\end{array}$ \\
\hline 3 & $\begin{array}{c}621.02 \\
827.691\end{array}$ & $\begin{array}{l}4+ \\
3+\end{array}$ & $\begin{array}{c}2480.049 \\
2480.05\end{array}$ & $\begin{array}{l}\text { T2-T3 } \\
\text { T2-T3 }\end{array}$ & $\begin{array}{l}\text { GSHMASMTGGQQMGRDPNSSSVDK + } 1 \text { oxidation } \\
\text { GSHMASMTGGQQMGRDPNSSSVDK + } 1 \text { oxidation }\end{array}$ \\
\hline 4 & $\begin{array}{l}621.020 \\
827.691 \\
847.357\end{array}$ & $\begin{array}{l}4+ \\
3+ \\
3+\end{array}$ & $\begin{array}{l}2480.049 \\
2480.05 \\
2539.049\end{array}$ & $\begin{array}{l}\text { T2-T3 } \\
\text { T2-T3 } \\
-\end{array}$ & $\begin{array}{l}\text { GSHMASMTGGQQMGRDPNSSSVDK + } 1 \text { oxidation } \\
\text { GSHMASMTGGQQMGRDPNSSSVDK + } 1 \text { oxidation } \\
\text { - }\end{array}$ \\
\hline 5 & $\begin{array}{l}621.017 \\
827.688\end{array}$ & $\begin{array}{l}4+ \\
3+\end{array}$ & $\begin{array}{l}2480.041 \\
2480.041\end{array}$ & $\begin{array}{l}\text { T2-T3 } \\
\text { T2-T3 }\end{array}$ & $\begin{array}{l}\text { GSHMASMTGGQQMGRDPNSSSVDK + } 1 \text { oxidation } \\
\text { GSHMASMTGGQQMGRDPNSSSVDK + } 1 \text { oxidation }\end{array}$ \\
\hline 6 & $\begin{array}{l}617.022 \\
822.360 \\
842.025\end{array}$ & $\begin{array}{l}4+ \\
3+ \\
3+\end{array}$ & $\begin{array}{l}2464.057 \\
2464.058 \\
2523.054\end{array}$ & $\begin{array}{l}\text { T2-T3 } \\
\text { T2-T3 } \\
-\end{array}$ & $\begin{array}{l}\text { GSHMASMTGGQQMGRDPNSSSVDK } \\
\text { GSHMASMTGGQQMGRDPNSSSVDK } \\
\text { - }\end{array}$ \\
\hline 7 & $\begin{array}{l}498.569 \\
747.352 \\
996.133\end{array}$ & $\begin{array}{l}3+ \\
2+ \\
3+\end{array}$ & $\begin{array}{l}1492.686 \\
1492.689 \\
2985.378\end{array}$ & $\begin{array}{l}\text { T7 / T13 } \\
\text { T7 / T13 } \\
\quad-\end{array}$ & $\begin{array}{l}\text { GETTTEAVDAATAEK } \\
\text { GETTTEAVDAATAEK } \\
-\end{array}$ \\
\hline 8 & $\begin{array}{l}498.273 \\
612.645 \\
747.352 \\
918.464\end{array}$ & $\begin{array}{l}2+ \\
3+ \\
2+ \\
2+\end{array}$ & $\begin{array}{l}994.531 \\
1834.914 \\
1492.689 \\
1834.913\end{array}$ & $\begin{array}{c}\text { T4 } \\
\text { T6-T7 / } \\
\text { T12-T13 } \\
\text { T7 / T13 } \\
\text { T6-T7 / } \\
\text { T12-T13 }\end{array}$ & $\begin{array}{l}\text { LAAALETYK + } \mathbf{1} \text { oxidation } \\
\text { TLKGETTTEAVDAATAEK } \\
\text { GETTTEAVDAATAEK } \\
\text { TLKGETTTEAVDAATAEK }\end{array}$ \\
\hline 9 & $\begin{array}{l}490.276 \\
979.546\end{array}$ & $\begin{array}{l}2+ \\
1+\end{array}$ & $\begin{array}{l}978.537 \\
978.539\end{array}$ & $\begin{array}{l}\mathrm{T} 4 \\
\mathrm{~T} 4\end{array}$ & $\begin{array}{l}\text { LAAALETYK } \\
\text { LAAALETYK }\end{array}$ \\
\hline 10 & $\begin{array}{c}726.634 \\
768.854 \\
1089.447\end{array}$ & $\begin{array}{l}3+ \\
2+ \\
2+\end{array}$ & $\begin{array}{l}2176.879 \\
1535.693 \\
2176.88\end{array}$ & $\begin{array}{l}\text { T9 / T15 } \\
\text { T2 } \\
\text { T9 / T15 }\end{array}$ & $\begin{array}{l}\text { QYANDNGVDGEWTYDDATK + } 1 \text { oxidation } \\
\text { GSHMASMTGGQQMGR } \\
\text { QYANDNGVDGEWTYDDATK }+\mathbf{1} \text { oxidation }\end{array}$ \\
\hline 12 & $\begin{array}{c}721.303 \\
726.979 \\
728.630 \\
733.951 \\
1081.452\end{array}$ & $\begin{array}{l}3+ \\
3+ \\
3+ \\
3+ \\
2+\end{array}$ & $\begin{array}{l}2160.889 \\
2177.914 \\
2182.867 \\
2198.832 \\
2160.889\end{array}$ & $\begin{array}{l}\text { T9 / T15 } \\
\text { T9 / T15 } \\
\text { T9 / T15 } \\
\text { T9 / T15 } \\
\text { T9 / T15 }\end{array}$ & $\begin{array}{l}\text { QYANDNGVDGEWTYDDATK } \\
\text { QYANDNGVDGEWTYDDATK + 1 oxidation + deamidation } \\
\text { QYANDNGVDGEWTYDDATK + Sodium } \\
\text { QYANDNGVDGEWTYDDATK + Potassium } \\
\text { QYANDNGVDGEWTYDDATK }\end{array}$ \\
\hline 13 & $\begin{array}{c}711.311 \\
716.987 \\
718.638 \\
723.960 \\
885.454 \\
886.125 \\
1066.464\end{array}$ & $\begin{array}{l}3+ \\
3+ \\
3+ \\
3+ \\
3+ \\
3+ \\
2+\end{array}$ & $\begin{array}{l}2130.912 \\
2147.939 \\
2152.891 \\
2168.857 \\
2653.345 \\
2655.352 \\
2130.914\end{array}$ & $\begin{array}{l}\text { T22 } \\
\text { T22 } \\
\text { T22 } \\
\text { T22 } \\
\mathrm{T} 10 / \mathrm{T} 16 \\
\mathrm{~T} 10 / \mathrm{T} 16 \\
\mathrm{~T} 22\end{array}$ & $\begin{array}{l}\text { QYANDNGVDGVWTYDDATK } \\
\text { QYANDNGVDGVWTYDDATK + 1 oxidation + deamidation } \\
\text { QYANDNGVDGVWTYDDATK + Sodium } \\
\text { QYANDNGVDGVWTYDDATK + Potassium } \\
\text { TFTVTEKPEVIDASELTPAVTTYK + Co form. by oxidation } \\
\text { TFTVTEKPEVIDASELTPAVTTYK + 1 oxidation } \\
\text { QYANDNGVDGVWTYDDATK }\end{array}$ \\
\hline 14 & $\begin{array}{c}885.450 \\
886.125 \\
1072.933 \\
1081.445 \\
1083.921\end{array}$ & $\begin{array}{l}3+ \\
3+ \\
2+ \\
2+ \\
2+\end{array}$ & $\begin{array}{l}2653.333 \\
2655.352 \\
2143.851 \\
2160.876 \\
2165.828\end{array}$ & $\begin{array}{l}\mathrm{T} 10 / \mathrm{T} 16 \\
\mathrm{~T} 10 / \mathrm{T} 16 \\
\mathrm{~T} 9 / \mathrm{T} 15 \\
\mathrm{~T} 9 / \mathrm{T} 15 \\
\mathrm{~T} 9 / \mathrm{T} 15\end{array}$ & $\begin{array}{l}\text { TFTVTEKPEVIDASELTPAVTTYK + co form. by oxidation } \\
\text { TFTVTEKPEVIDASELTPAVTTYK + } \mathbf{1} \text { oxidation } \\
\text { pQYANDNGVDGEWTYDDATK } \\
\text { QYANDNGVDGEWTYDDATK } \\
\text { pQYANDNGVDGEWTYDDATK + Sodium }\end{array}$ \\
\hline 15 & $\begin{array}{c}866.121 \\
880.794 \\
1320.687\end{array}$ & $\begin{array}{l}3+ \\
3+ \\
2+\end{array}$ & $\begin{array}{l}2595.341 \\
2639.360 \\
2639.359\end{array}$ & $\begin{array}{l}- \\
\mathrm{T} 10 / \mathrm{T} 16 \\
\mathrm{~T} 10 / \mathrm{T} 16\end{array}$ & $\begin{array}{l}\text { - } \\
\text { TFTVTEKPEVIDASELTPAVTTYK } \\
\text { TFTVTEKPEVIDASELTPAVTTYK }\end{array}$ \\
\hline
\end{tabular}




\begin{tabular}{cccccl}
\hline fr. no. & $\mathbf{m} / \mathbf{z}$ & $\mathbf{z}$ & exp. mass & T no. $^{\text {b) }}$ & amino acid sequence / oxidation \\
\hline \multirow{2}{*}{16} & 895.131 & $3+$ & 2682.370 & - & - \\
& 900.806 & $3+$ & 2699.397 & - & - \\
1342.194 & $2+$ & 2682.373 & - & - \\
& 1035.402 & $8+$ & 8275.159 & T16-T23 & TFTVTEKPEVIDASELTPAVTTYKLVINGKTLKGETTTKAVDA \\
& 1183.030 & $7+$ & 8274.162 & T16-T23 & ETAEKAFKQYANDNGVDGVWTYDDATKTFTVTE \\
& 1380.201 & $6+$ & 8275.160 & T16-T23 & \\
17 & 1072.421 & $8+$ & 8571.311 & T4-T10 & LAAALETYKLILNGKTLKGETTTEAVDAATAEKVFKQYAND \\
& 1225.624 & $7+$ & 8572.319 & T4-T10 & NGVDGEWTYDDATKTFTVTEKPEVIDASELTPAVTTYK \\
& 1429.728 & $6+$ & 8572.323 & T4-T10 & \\
& 1136.465 & $9+$ & 10219.121 & T10-T16 & TFTVTEKPEVIDASELTPAVTTYKLVINGKTLKGETTTEAVD \\
& 1278.396 & $8+$ & 10219.113 & T10-T16 & AATAEKVFKQYANDNGVDGEWTYDDATKTFTVTEKPEVI \\
& 1460.879 & $7+$ & 10219.103 & T10-T16 & DASELTPAVTTYK \\
\hline
\end{tabular}

a) cf. figure $3 \mathrm{~B}$

b) tryptic peptide number, see figure 2

"-": not assigned

Supplemental Table 7: Collisional cross sections of charged molecular ions.

\begin{tabular}{|c|c|c|}
\hline charge state & \multicolumn{2}{|c|}{$\operatorname{CCS}\left[\AA^{2}\right]$} \\
\hline $8+$ & $2540 \pm 19^{a)}$ & n.d. \\
\hline $9+$ & $2422 \pm 14^{\text {a) }}$ & n.d. \\
\hline $10+$ & $2446 \pm 13^{a)}$ & n.d. \\
\hline $19+$ & n.d. & $6143 \pm 10^{b)}$ \\
\hline $20+$ & n.d. & $6167 \pm 24^{b)}$ \\
\hline $21+$ & n.d. & $6165 \pm 27^{b)}$ \\
\hline $22+$ & n.d. & $6192 \pm 26^{b)}$ \\
\hline $23+$ & n.d. & $6261 \pm 8^{b)}$ \\
\hline $24+$ & n.d. & $6327 \pm 17^{b)}$ \\
\hline $25+$ & n.d. & $6448 \pm 12^{b)}$ \\
\hline $26+$ & n.d. & $6541 \pm 16^{b)}$ \\
\hline $27+$ & n.d. & $6699 \pm 15^{b)}$ \\
\hline
\end{tabular}

a) average of 3 measurements at wave velocities 700,800 , and $900 \mathrm{~m} / \mathrm{s}$

b) average of 3 measurements at wave heights 30,35 , and $40 \mathrm{~V}$ 


\section{Supplemental Figures}

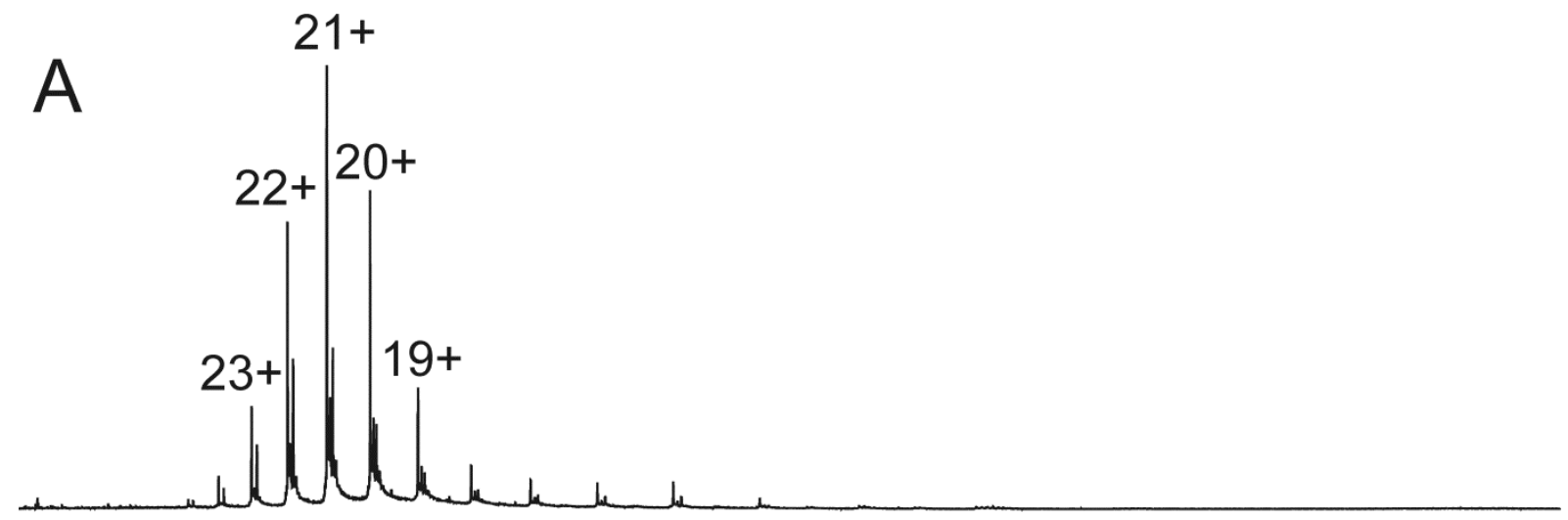

B
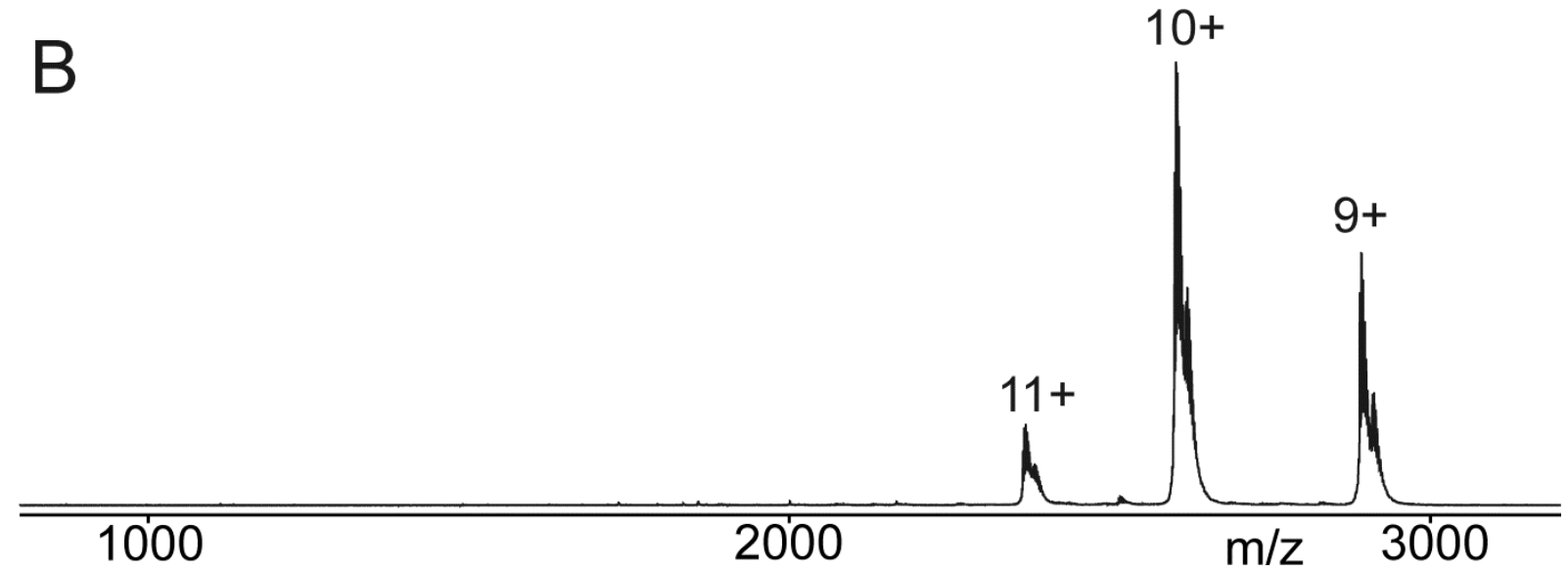

Supplemental Figure 1: NanoESI mass spectra of protein G'e in positive-ion mode. A: Protein G'e was sprayed from $2 \%$ aqueous acetic acid:methanol (95:5, v/v), pH 2.5. B: Protein G'e was sprayed from 50 mM aqueous ammonium acetate:methanol (95:5, v/v), pH 7. Multiply protonated protein ion signals are labeled with charge numbers. 


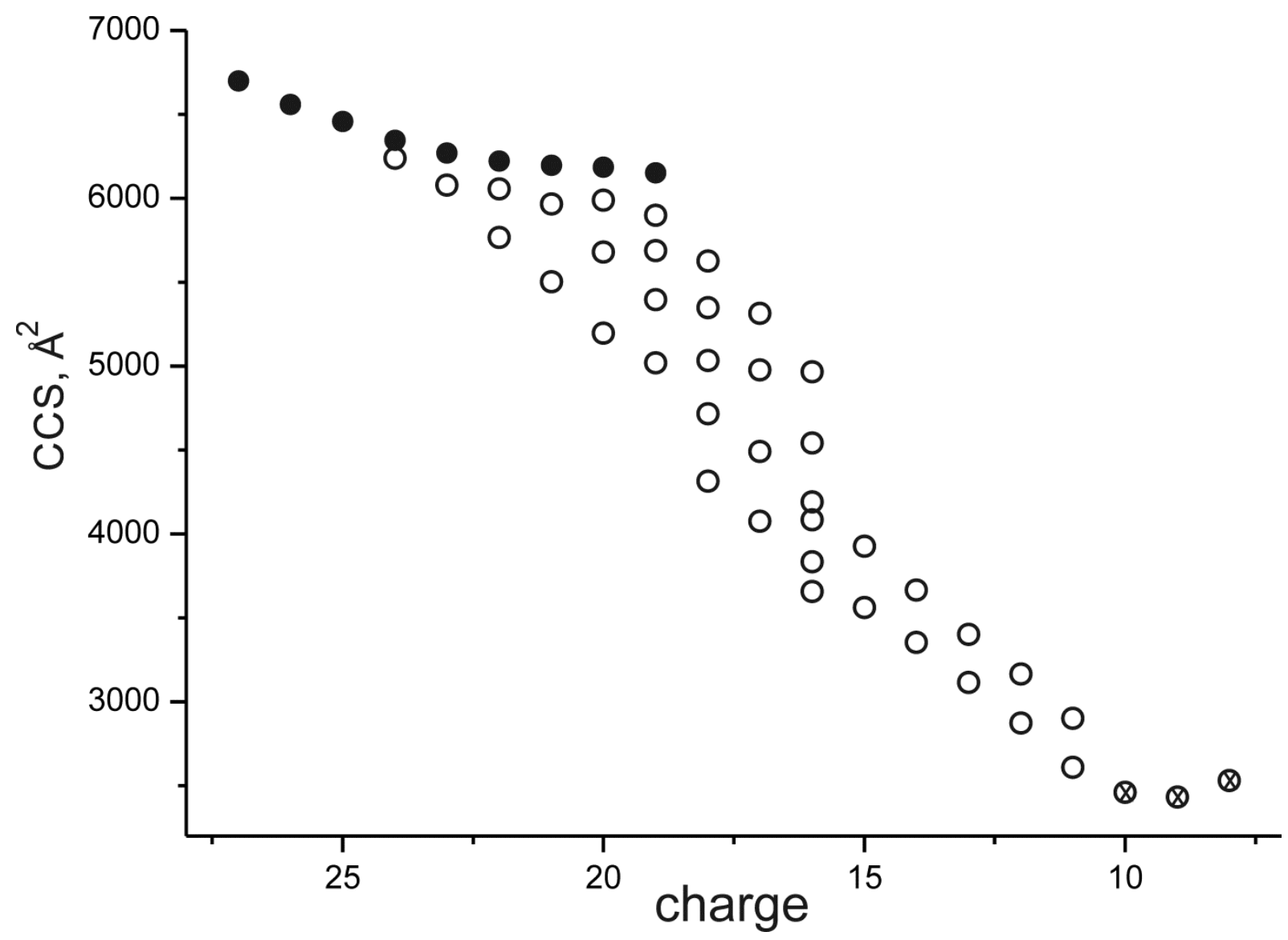

Supplemental Figure 2: Experimentally determined CCS values of protein G'e. Closed circles represent conformations of protein G'e charge states $19+$ to $27+$ when sprayed from $2 \%$ aqueous acetic acid:methanol $(95: 5, \mathrm{v} / \mathrm{v}), \mathrm{pH} 2.5$. Open circles depict multiple conformations of charge states $8+$ to $24+$ of protein $G^{\prime}$ e coexisting in the gas phase when sprayed from $50 \mathrm{mM}$ aqueous ammonium acetate:methanol (95:5, v/v), $\mathrm{pH}$ 7. Circles marked with " $x$ " represent compactly folded ions (charge states $19+$ to $27+$ and $8+$ to $10+$ ) with just one conformation (cf. Figure 1 and Supplemental Figure 2). 


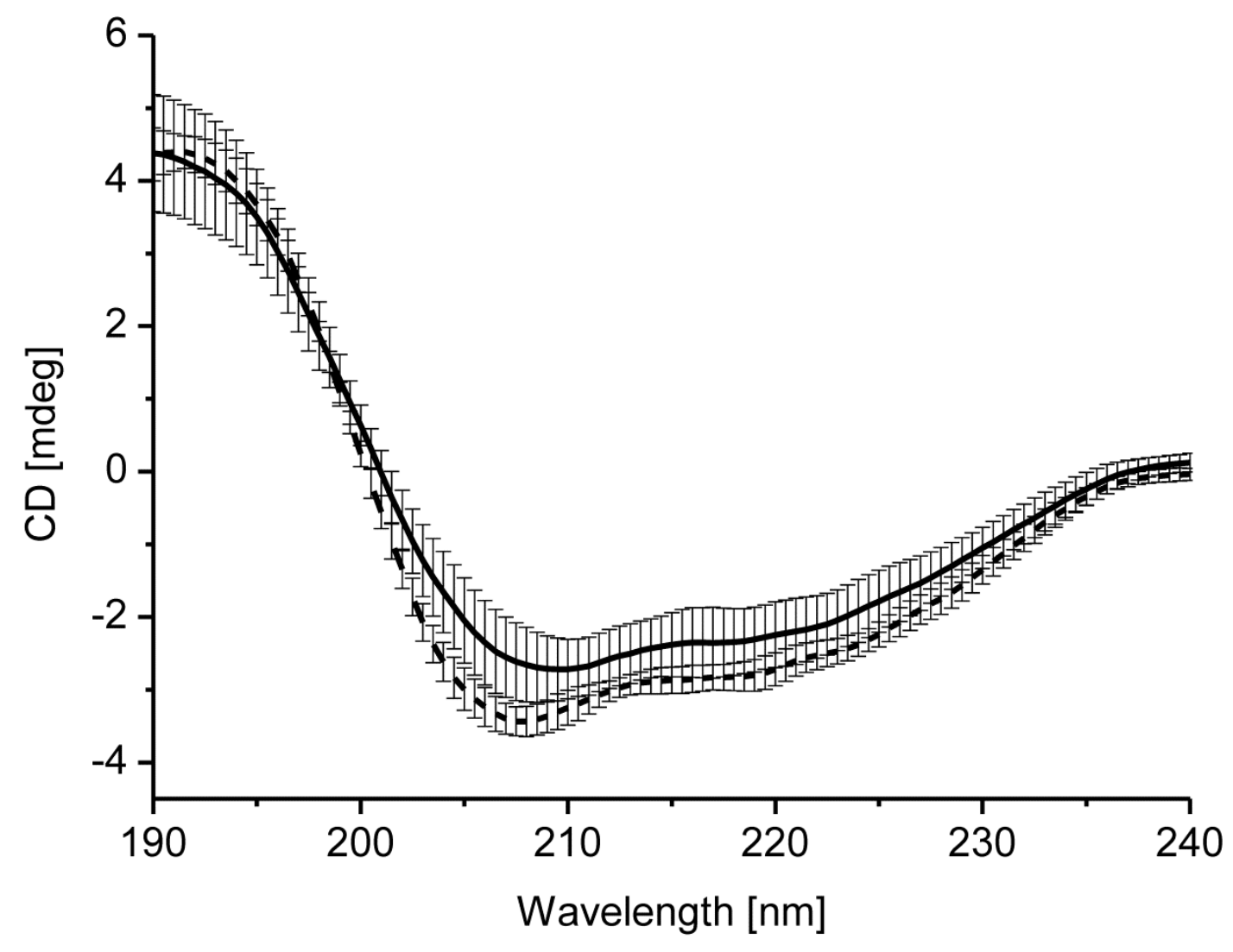

Supplemental Figure 3: Circular dichroism spectrum in the far UV-region of protein G'e in $10 \mathrm{mM}$ ammonium acetate buffer, $\mathrm{pH} 7$ (solid line: average of 6 measurements), and of protein G'e in 2\% acetic acid, $\mathrm{pH} 2.5$ (dashed line: average of 6 measurements), respectively. Standard deviations are shown. For details on secondary structure contents see supplemental tables 1 and 2 . 

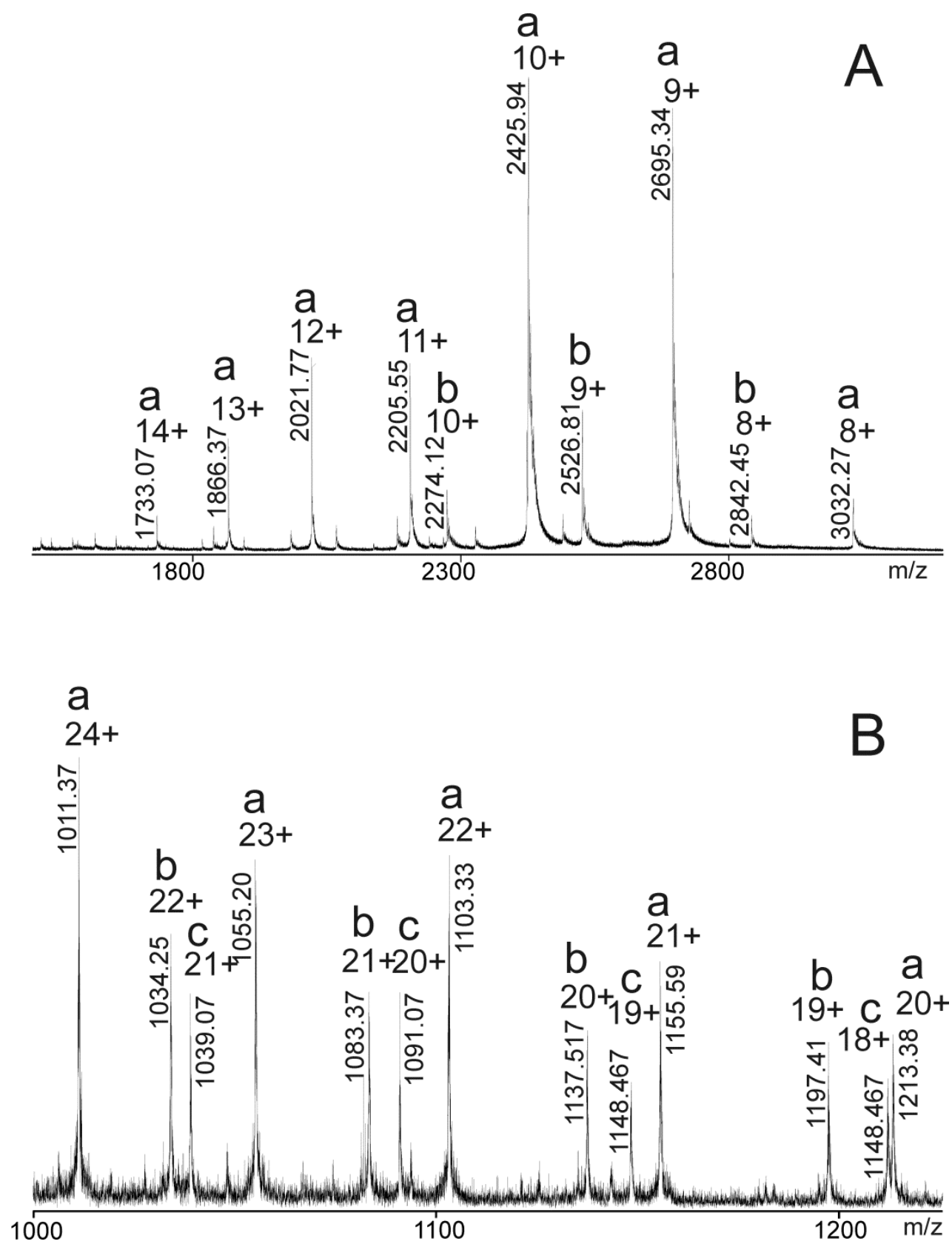

Supplemental Figure 4: NanoESI-MS of large protein G'e fragments produced by limited digestion with trypsin followed by buffer exchange using centrifugal spin columns (solvent: 50 $\mathrm{mM}$ ammonium acetate, $\mathrm{pH}$ 7). B: NanoESI-MS of large protein G'e fragments produced by limited digestion with trypsin followed by buffer exchange using centrifugal spin columns (solvent: $2 \%$ acetic acid, $\mathrm{pH}$ 2.5). "a", "b" and "c" represent ion series that were assigned to the partial amino acid sequences aa17-241, aa32-241, and aa41-241 with molecular weights of 24,249.94 Da, 22,732.48 Da, and 21,800.60 Da, respectively (cf. Figure 2). For CCS value assignments see supplemental table 3 . 


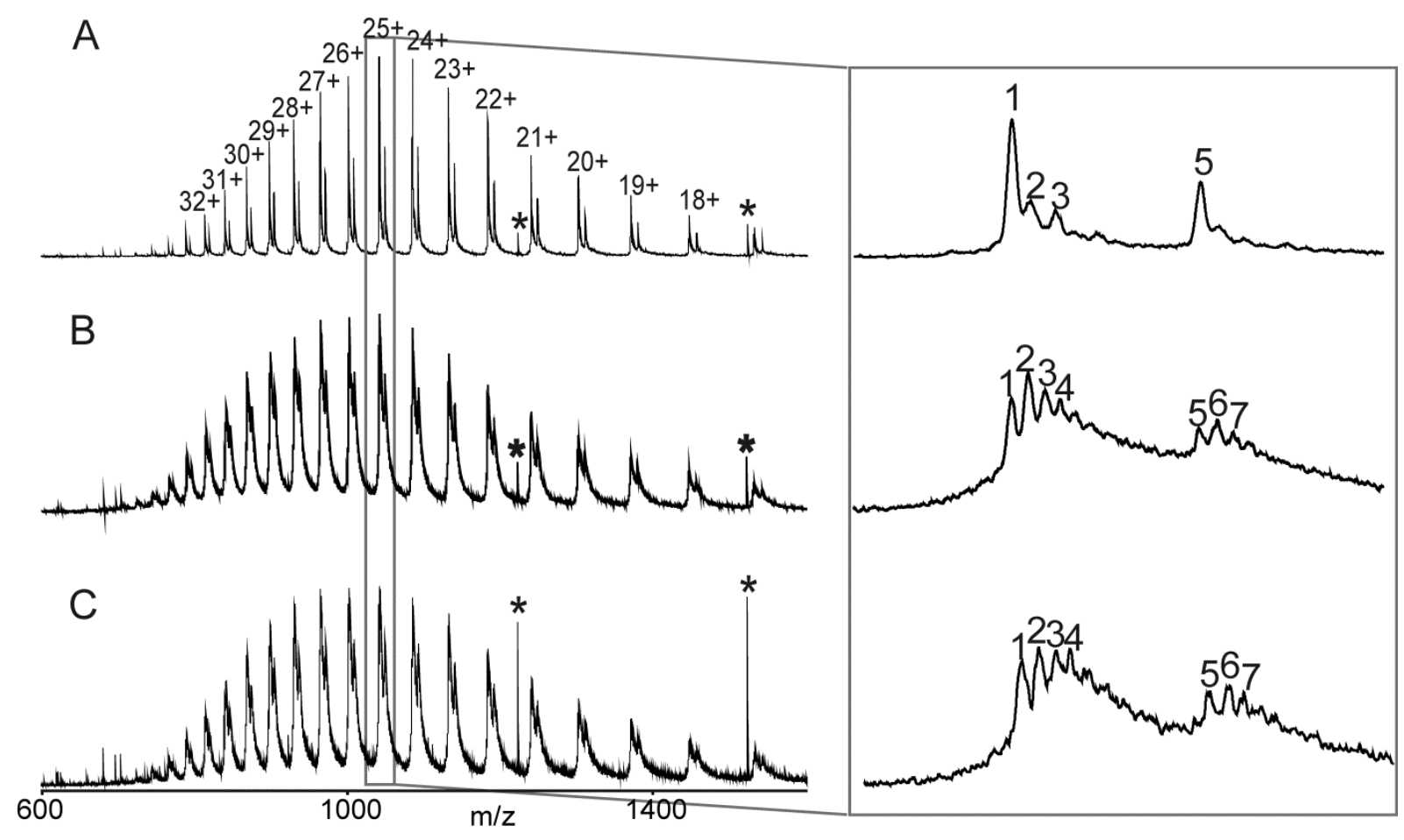

Supplemental Figure 5: NanoESI mass spectra of protein G'e after oxidation. A: Protein G'e in 2\% acetic acid, pH $2.5\left(\mathrm{H}_{2} \mathrm{O}_{2}\right.$ control, no laser irradiation). B: FPOP of protein G'e in $2 \%$ acetic acid, $\mathrm{pH}$ 2.5. C: FPOP of protein G'e in $50 \mathrm{mM}$ ammonium acetate, $\mathrm{pH}$ 6.9. “””: internal standard. The inserts show the $25+$ ion signals for the unmodified protein G'e (1) and its oxidation products (2-4) as well as for the ion signal of the gluconoylated protein G'e (5) and its oxidation products (6 and 7$)$. 


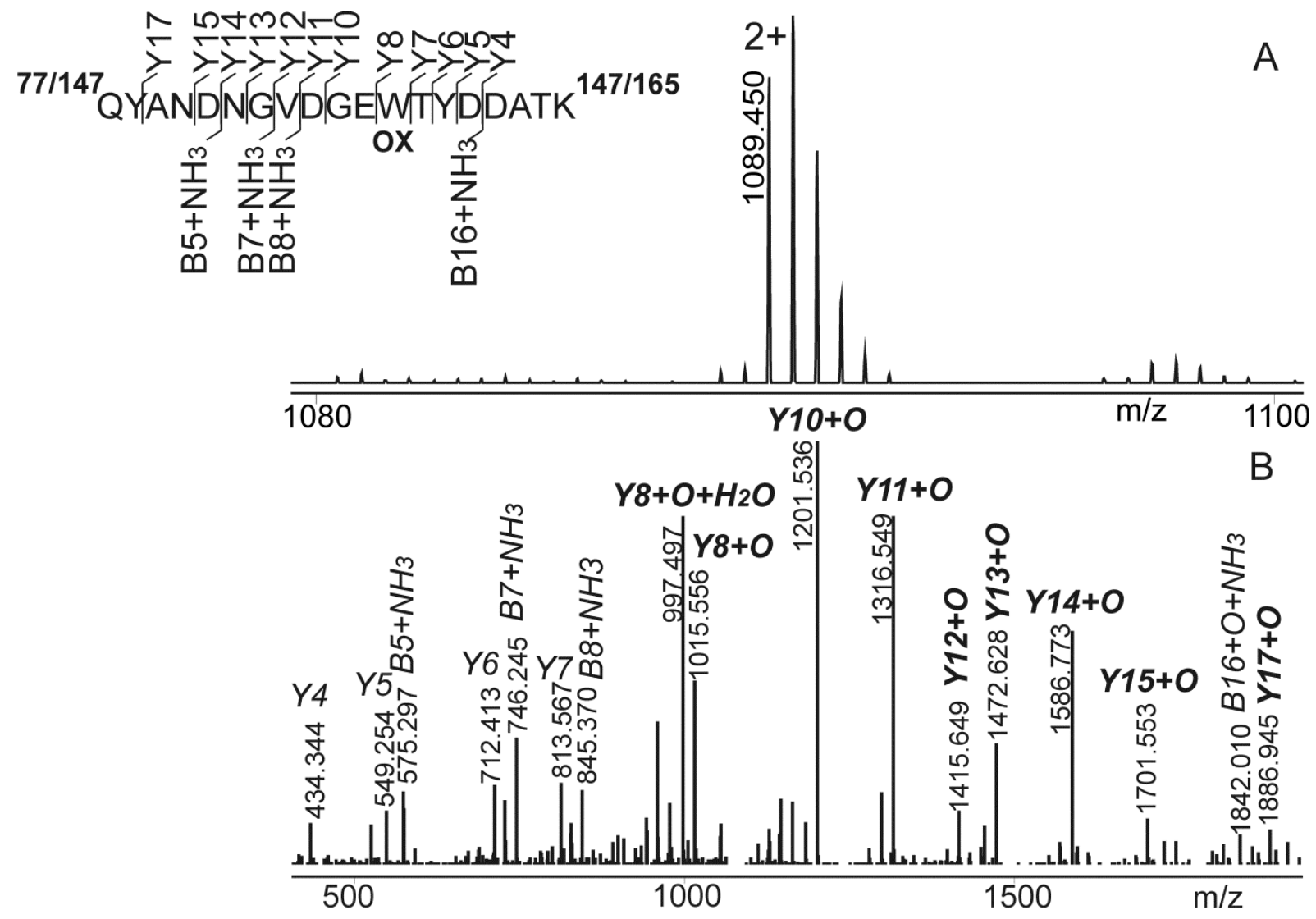

Supplemental Figure 6: Peak 10 of the nanoLC-ESI-MS run of protein G'e-derived tryptic peptides after FPOP in $50 \mathrm{mM}$ ammonium acetate (cf. Figure 3A). A: The mass spectrum shows an ion signal at $\mathrm{m} / \mathrm{z} 1089.450$ which is assigned to peptide T9 and/or T15 with one oxidation. For ion signal assignments see supplemental table 6. B: MS/MS fragment ions from the precursor ion at $m / z 1089.450$. The corresponding amino acid sequence is shown in the insert and the oxidation site on W88 and/or W158 is depicted together with the fragment ion type assignments. B-type and Y"-type fragment ion signals are labeled; Y"n are labeled as $\mathrm{Yn}$ for simplicity. 


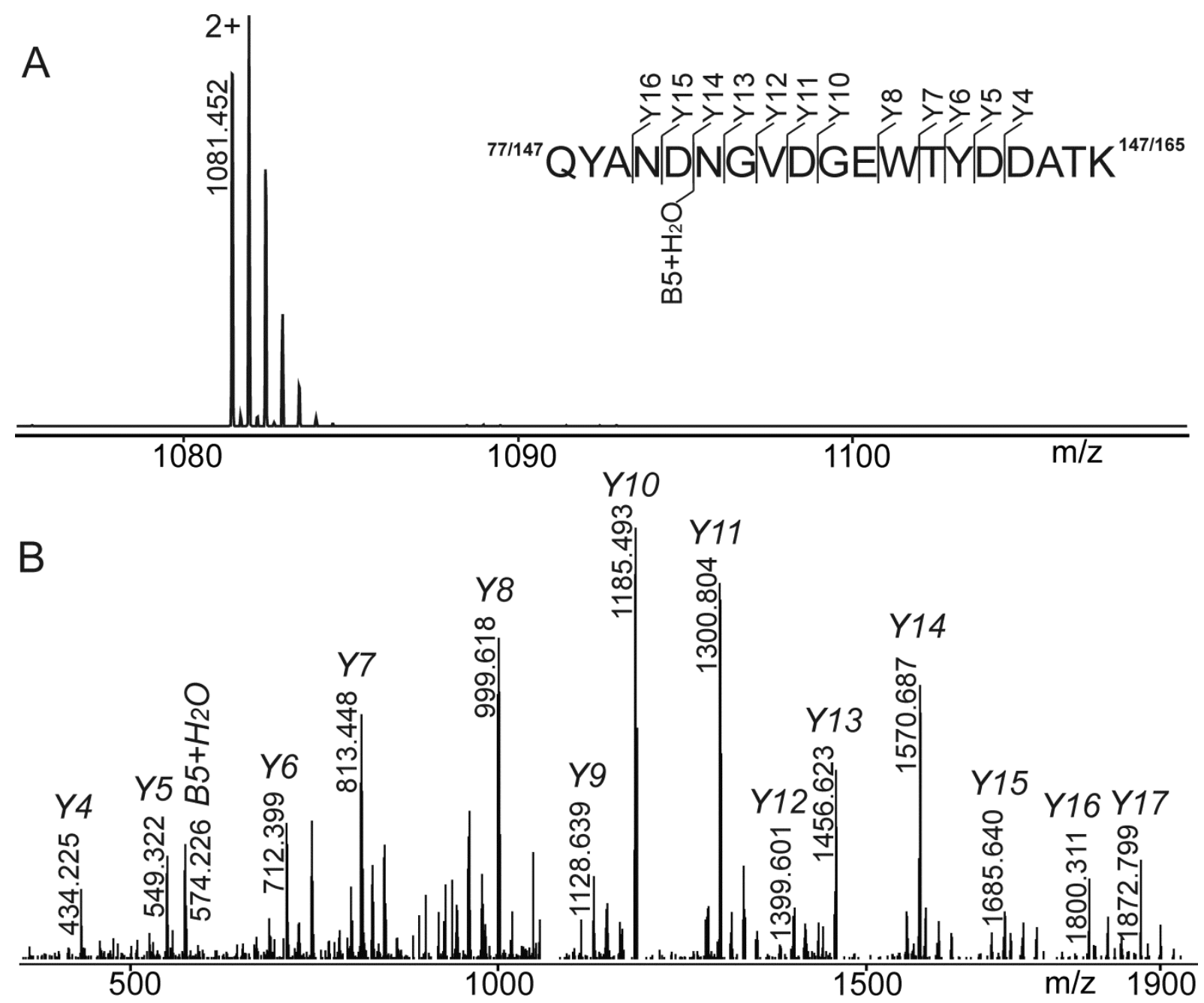

Supplemental Figure 7: Peak 12 of the nanoLC-ESI-MS run of protein G'e-derived tryptic peptides after FPOP in $50 \mathrm{mM}$ ammonium acetate (cf. Figure 3A). A: The mass spectrum shows an ion signal at $\mathrm{m} / \mathrm{z} 1081.452$ which is assigned to peptide T9 and/or T15. For ion signal assignments see supplemental table 5. B: MS/MS fragment ions from the precursor ion at $m / z$ 1081.452. The corresponding amino acid sequence is shown in the insert and the fragment ion type assignments are given. B-type and Y"-type fragment ion signals are labeled; Y"n are labeled as Yn for simplicity. 


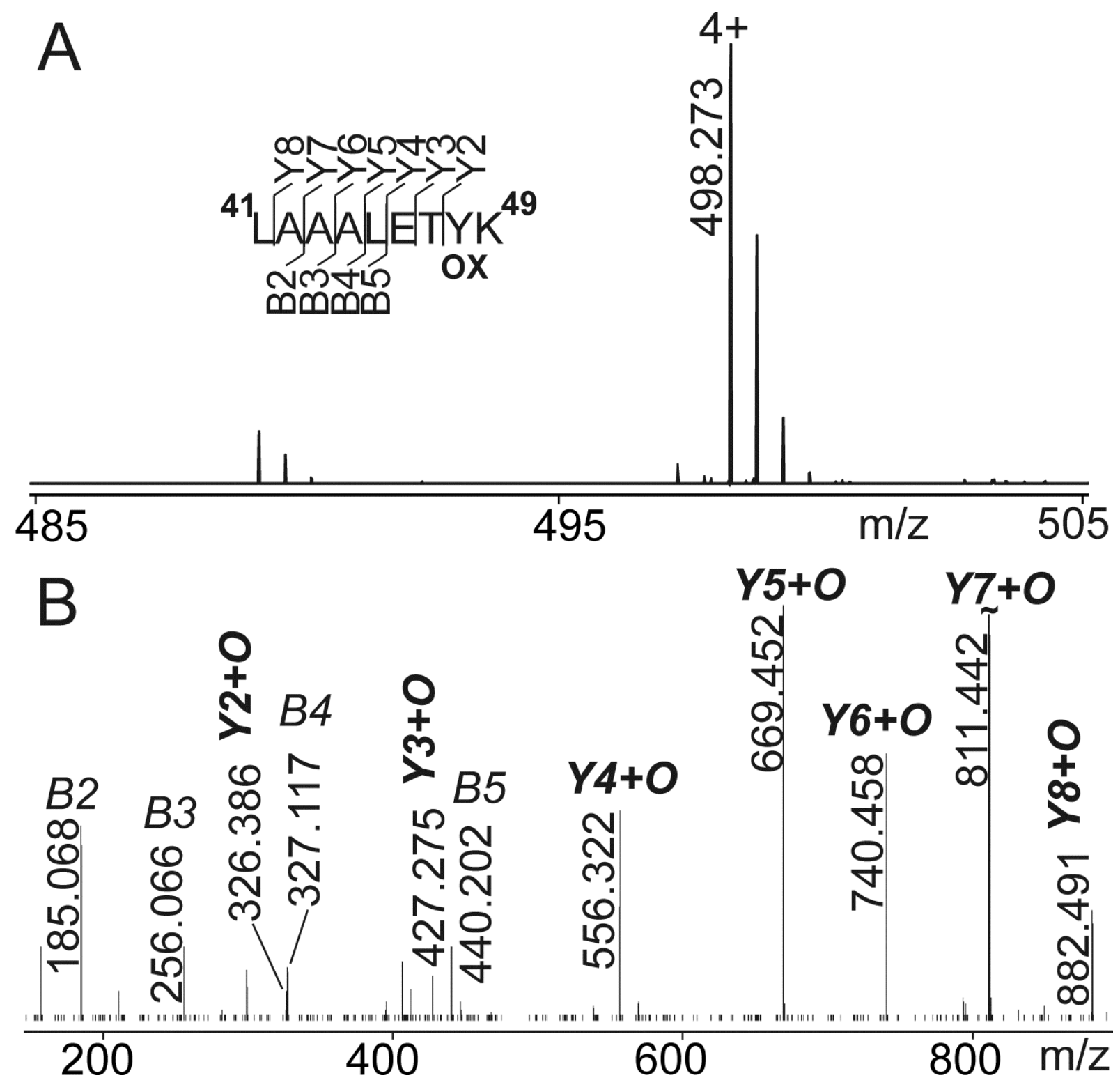

Supplemental Figure 8: Peak 8 of the nanoLC-ESI-MS run of protein G'e-derived tryptic peptides after FPOP in $2 \%$ acetic acid (cf. Figure 3B). A: The mass spectrum shows an ion of $m / z 498.273$ that is assigned to peptide T4 with one oxidation. For ion signal assignments see supplemental table 6. B: MS/MS fragment ions from the precursor ion of $m / z 498.273$. The corresponding amino acid sequence is shown in the insert, and oxidation on Y48 is depicted together with the fragment ion type assignments. B-type and Y"-type fragment ion signals are labeled; $Y " n$ are labeled as $Y n$ for simplicity. 


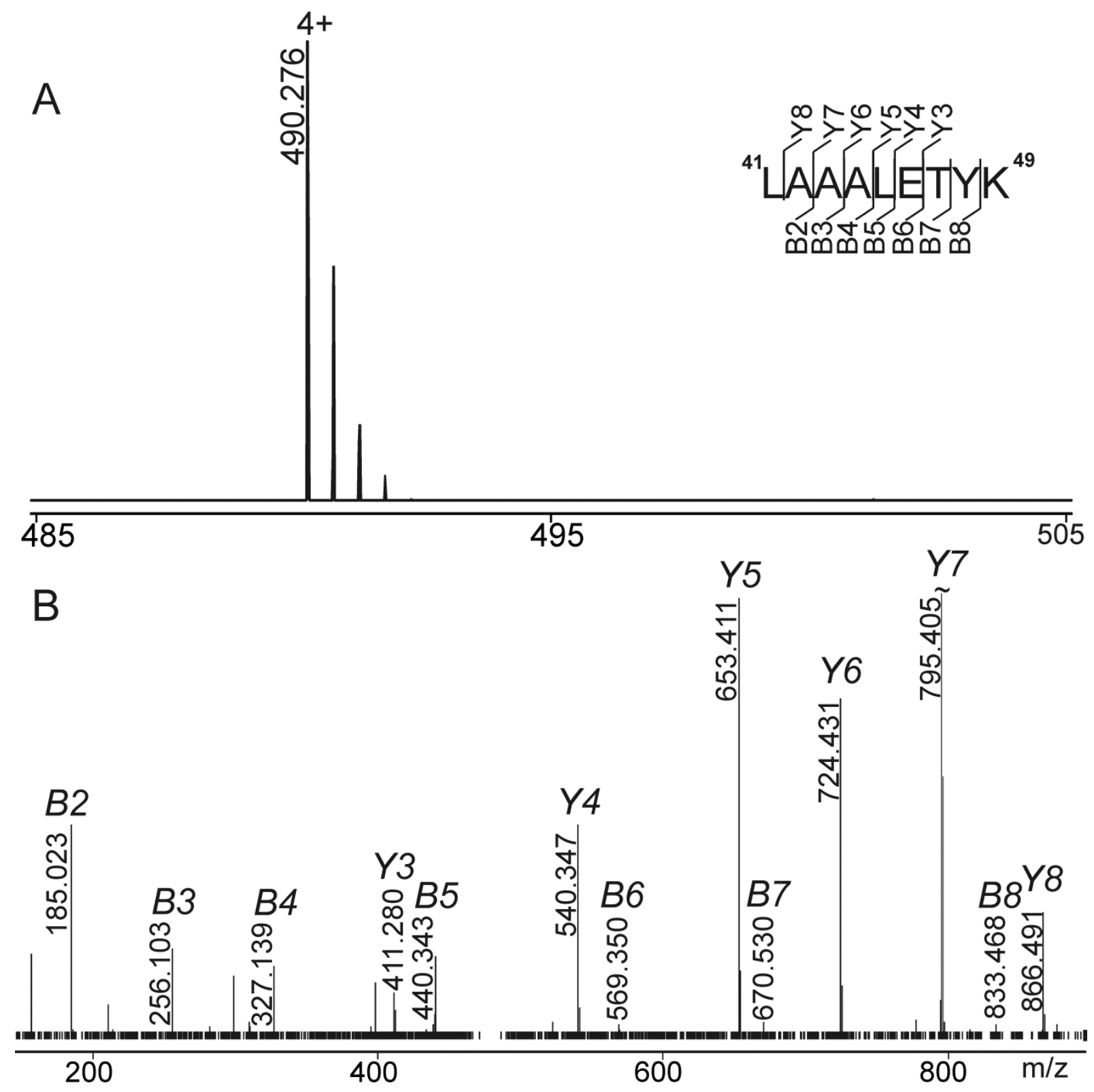

Supplemental Figure 9: Peak 9 of the nanoLC-ESI-MS run of protein G'e-derived tryptic peptides after FPOP in $50 \mathrm{mM}$ ammonium acetate (cf. Figure 3A). A: The mass spectrum shows an ion signal at $\mathrm{m} / \mathrm{z} 490.276$ which is assigned to peptide T4. For ion signal assignments see supplemental table 6. B: MS/MS fragment ions from the precursor ion at $m / z$ 490.276. The corresponding amino acid sequence together with the fragment ion type assignments is shown in the insert. B-type and Y"-type fragment ion signals are labeled; $Y " n$ are labeled as $\mathrm{Yn}$ for simplicity. 


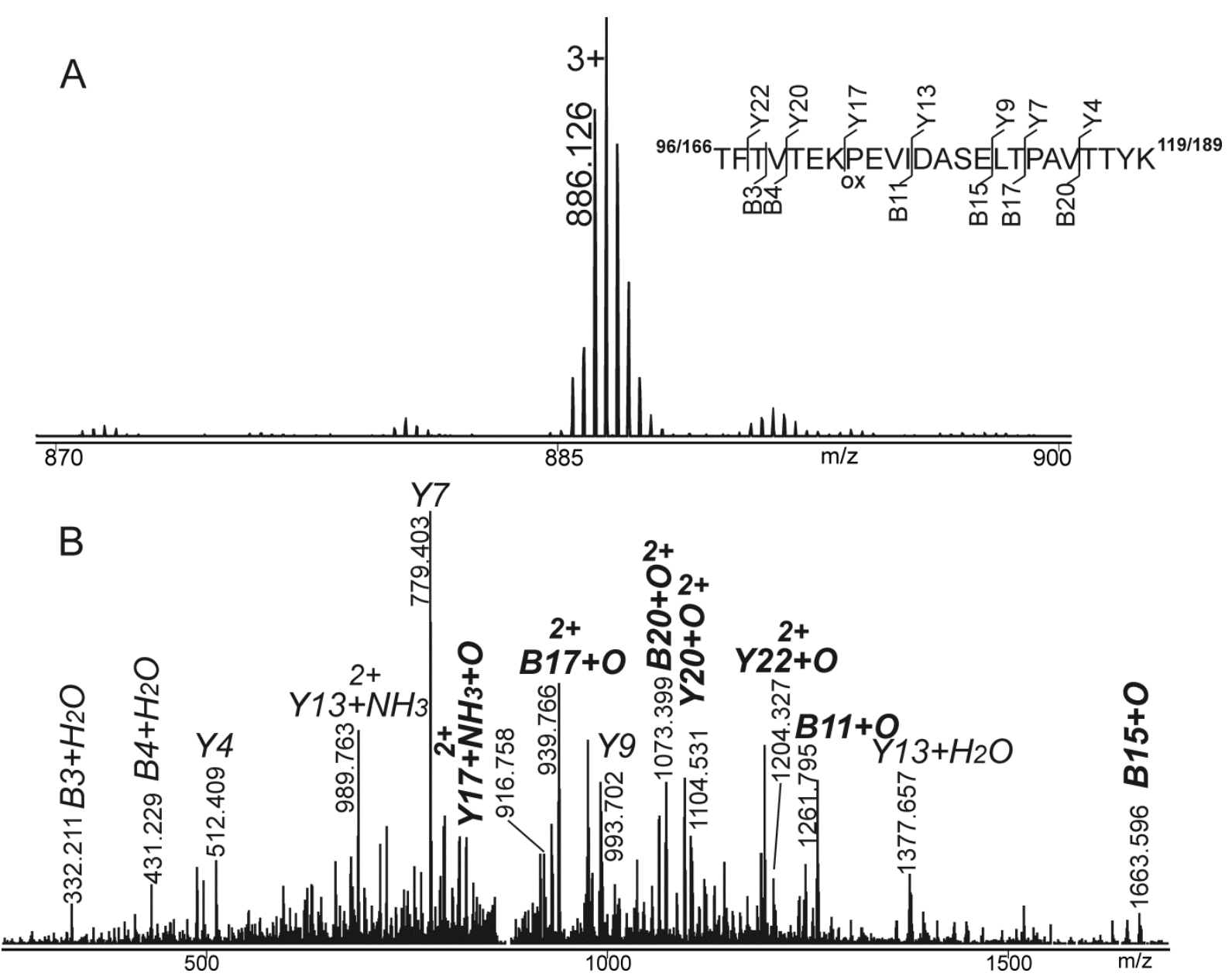

Supplemental Figure 10: Peak 14 of the nanoLC-ESI-MS run of protein G'e-derived tryptic peptides after FPOP in $50 \mathrm{mM}$ ammonium acetate (cf. Figure 3A). A: The mass spectrum shows an ion signal at $\mathrm{m} / \mathrm{z} 886.126$ which is assigned to peptide T10 and/or T16 with one oxidation. For ion signal assignments see supplemental table 5. B: MS/MS fragment ions from the precursor ion at $m / z$ 886.126. The corresponding amino acid sequence is shown in the insert and the oxidation site on $\mathrm{P} 103$ and/or $\mathrm{P} 173$ is depicted together with the fragment ion type assignments. B-type and Y"-type fragment ion signals are labeled; Y"n are labeled as $\mathrm{Yn}$ for simplicity. 


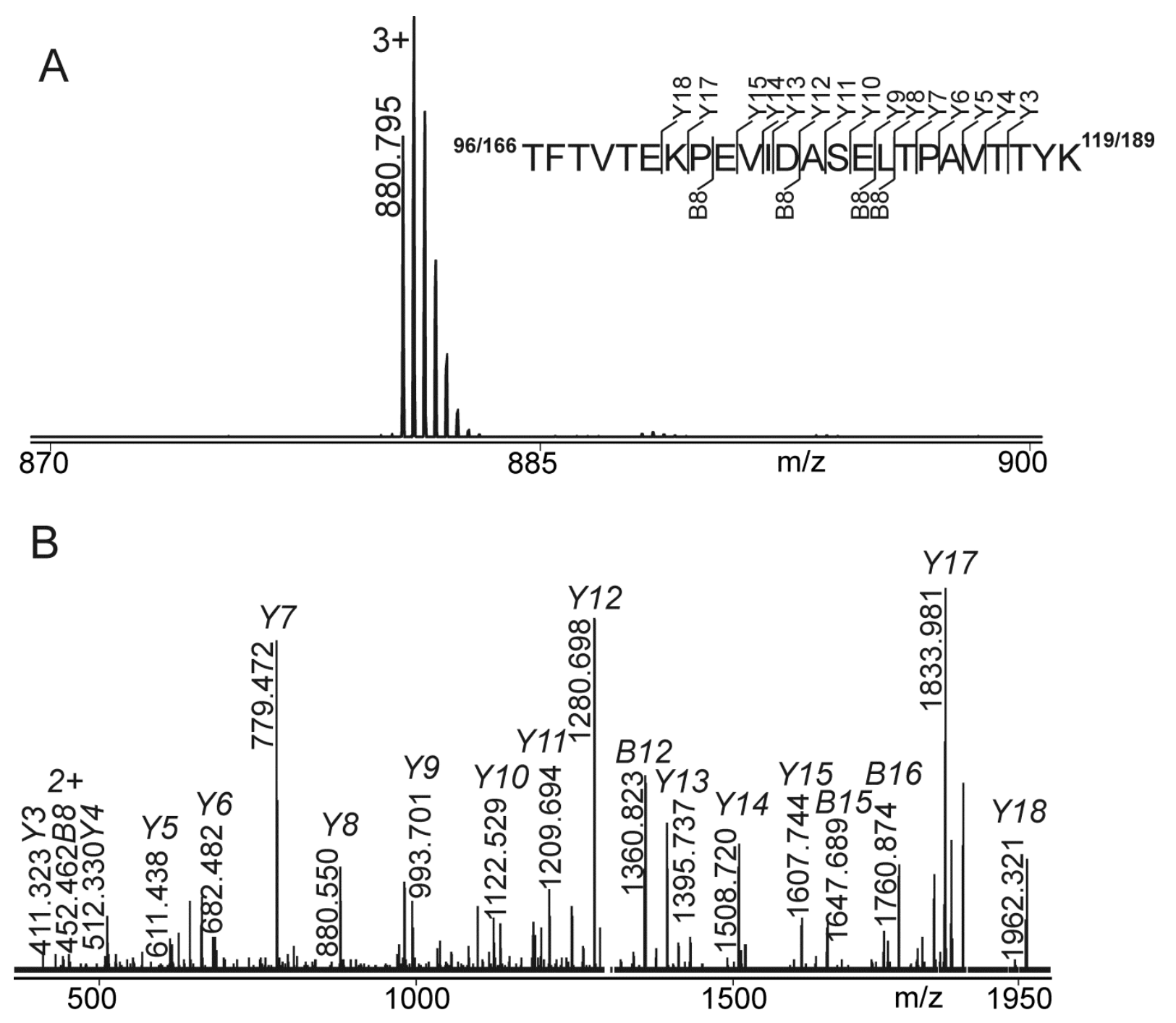

Supplemental Figure 11: Peak 15 of the nanoLC-ESI-MS run of protein G'e-derived tryptic peptides after FPOP in $50 \mathrm{mM}$ ammonium acetate (cf. Figure 3A). A: The mass spectrum shows an ion signal at $\mathrm{m} / \mathrm{z} 880.795$ which is assigned to peptide T10 and/or T16. For ion signal assignments see supplemental table 5. B: MS/MS fragment ions from the precursor ion at $m / z 880.795$. The corresponding amino acid sequence is shown in the insert and the fragment ion type assignments are given. B-type and $Y^{\prime \prime}$-type fragment ions are labeled; $Y$ "n are labeled as $\mathrm{Yn}$ for simplicity. 

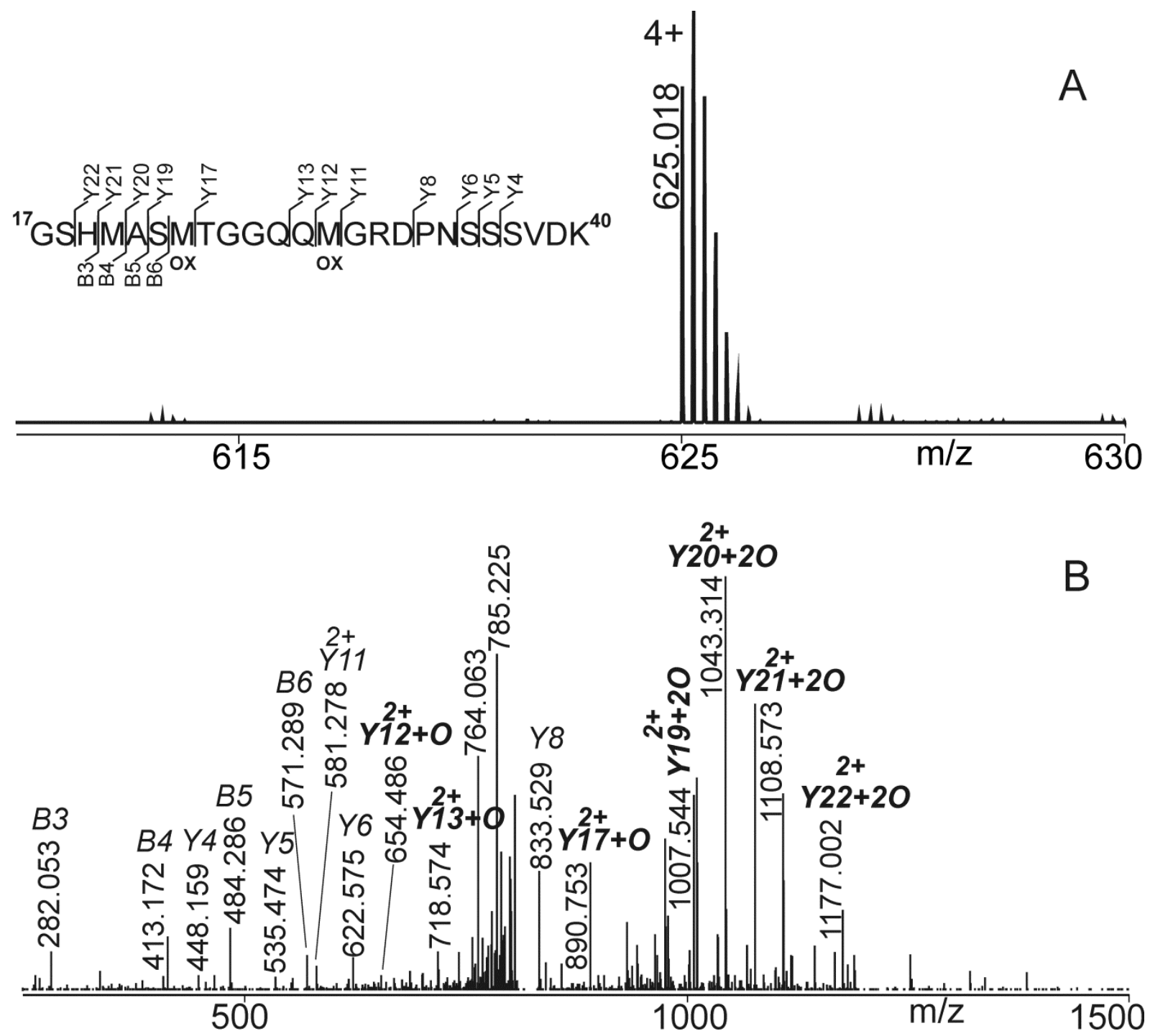

Supplemental Figure 12: Peak 2 of the nanoLC-ESI-MS run of protein G'e-derived tryptic peptides after FPOP in $50 \mathrm{mM}$ ammonium acetate (cf. Figure 3A). A: The mass spectrum shows an ion signal at $m / z 625.018$ which is assigned to peptide T2-T3 with two oxidations. For ion signal assignments see supplemental table 5. B: MS/MS fragment ions from the precursor ion at $m / z 625.018$. The corresponding amino acid sequence is shown in the insert and oxidation sites on M23 and M29 are depicted together with the fragment ion type assignments. B-type and Y"-type fragment ion signals are labeled; $Y " n$ are labeled as $Y n$ for simplicity. 


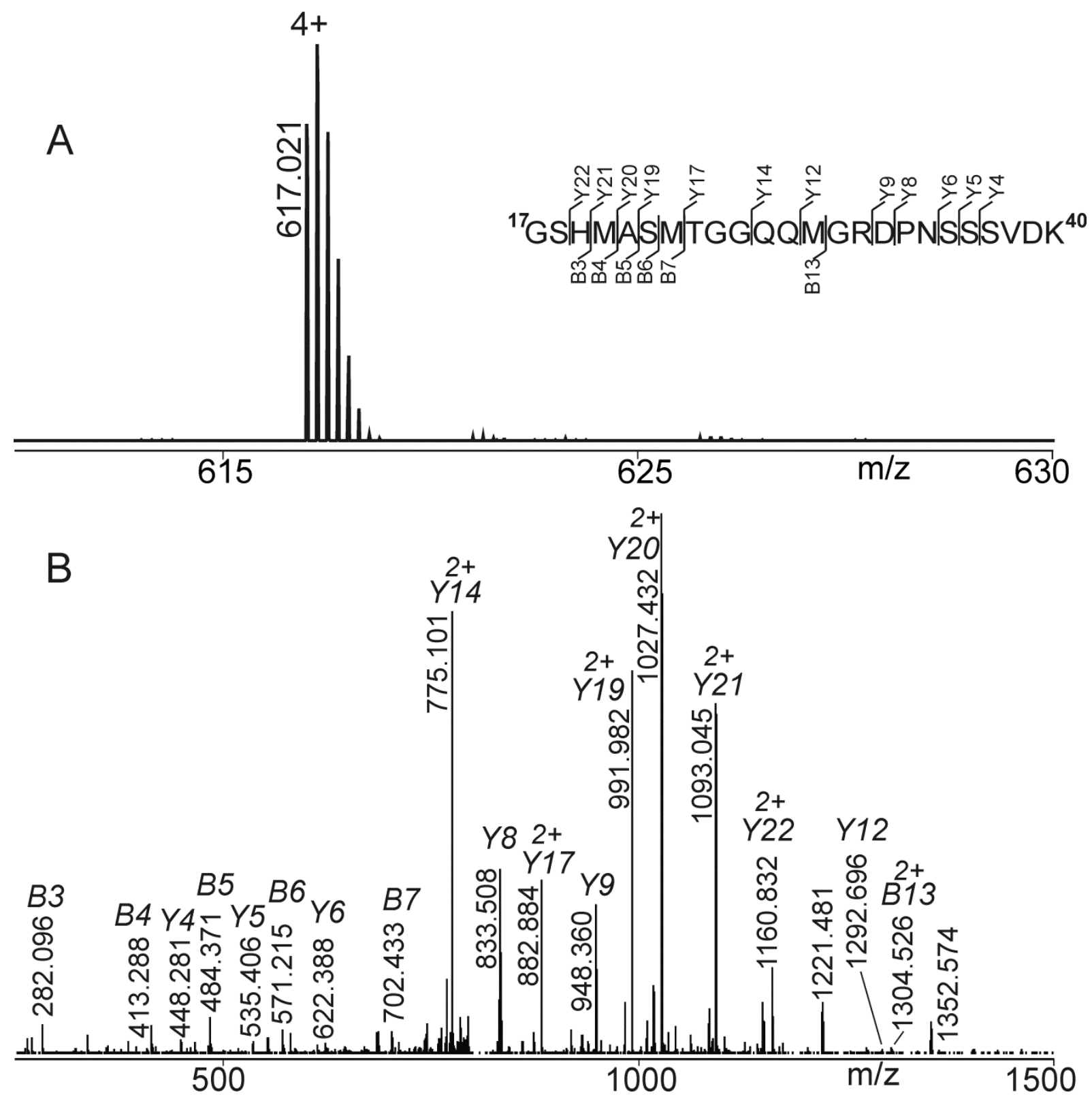

Supplemental Figure 13: Peak 6 of the nanoLC-ESI-MS run of protein G' e derived tryptic peptides after FPOP in $50 \mathrm{mM}$ ammonium acetate (cf. Figure 3A). A: The mass spectrum shows an ion signal at $m / z 617.021$ which is assigned to peptide T2-T3. For ion signal assignments see supplemental table 5. B: MS/MS fragment ions from the precursor ion at $m / z 617.021$. The corresponding amino acid sequence together with the fragment ion type assignments is shown in the insert. B-type and Y"-type fragment ion signals are labeled; $Y " n$ are labeled as $\mathrm{Yn}$ for simplicity. 